\title{
An off-line, numerically efficient initialization scheme in an oceanic general circulation model for El Niño-Southern Oscillation prediction
}

Youmin Tang, ${ }^{1}$ Richard Kleeman, ${ }^{1}$ Andrew M. Moore, ${ }^{2}$ Jérôme Vialard, ${ }^{3}$ and Anthony Weaver ${ }^{4}$

Received 10 October 2003; revised 11 March 2004; accepted 18 March 2004; published 8 May 2004.

[1] In this study a simplified initialization scheme, which is "off-line," is proposed and applied to an oceanic general circulation model (OGCM) for El Niño-Southern Oscillation (ENSO) prediction. The initialization scheme is based on the National Centers for Environmental Prediction ocean reanalysis and a two-dimensional variational (2D-Var) assimilation algorithm. It focuses on two basic issues in data assimilation: observed data and computational cost. Compared with a traditional assimilation system, this simplified scheme avoids model forward integration and the complications of acquiring and processing raw in situ temperature observations. The off-line scheme only requires around $1 / 20$ of the computational expense of a traditional algorithm. Two hybrid coupled models, an OGCM coupled to a statistical atmosphere, and the same ocean model coupled to a dynamical atmosphere, were used to examine the initialization scheme. A large ensemble of prediction experiments during the period from 1981 to 1998 shows that relative to just a wind forced initialization the off-line scheme leads to a significant improvement in predictive skills of Niño3 sea surface temperature anomaly (SSTA) for all lead times. The prediction skills obtained by the scheme is as high as that attained by a more traditional "on-line" assimilation scheme. INDEX TERMS: 4522 Oceanography: Physical: El Niño; 3337 Meteorology and Atmospheric Dynamics: Numerical modeling and data assimilation; 3339 Meteorology and Atmospheric Dynamics: Ocean/atmosphere interactions (0312, 4504); 4263

Oceanography: General: Ocean prediction; KEYWORDS: ENSO prediction, initialization, ocean model

Citation: Tang, Y., R. Kleeman, A. M. Moore, J. Vialard, and A. Weaver (2004), An off-line, numerically efficient initialization scheme in an oceanic general circulation model for El Niño-Southern Oscillation prediction, J. Geophys. Res., 109, C05014, doi:10.1029/2003JC002159.

\section{Introduction}

[2] There are generally three forms of errors, initial condition errors, model errors and data errors, that limit the skill of El Niño-Southern Oscillation (ENSO) dynamical prediction and contribute to the growth of forecast errors. One of these, the initial condition errors, has an extremely important impact on model skill as ENSO prediction is an initial value problem, and the future evolution of the system depends highly on the initial state from which it started. On the other hand, compared with

\footnotetext{
${ }^{1}$ Courant Institute of Mathematical Sciences, New York University, New York, New York, USA.

${ }^{2}$ Program for Atmosphere Ocean Science, University of Colorado, Boulder, Colorado, USA.

${ }^{3}$ Laboratoire d'Oceanographie Dynamique et de Climatologie, Paris, France.

${ }^{4}$ Climate Modeling and Global Change Group, Climate Modeling and Global Change Group Centre Europen de Recherche et de Formation Avance en Calcul Scientifique, Toulouse, France.

Copyright 2004 by the American Geophysical Union. 0148-0227/04/2003JC002159
}

the other two errors, the initial condition errors can be relatively easily reduced by data assimilation. Since the mid 1990's, large efforts have been made to develop initialization schemes to improve prediction skill and it has been found that initialization using subsurface temperature observations can significantly improve ENSO prediction skills [e.g., Kleeman et al., 1995; Ji et al., 2000; Segschneider et al., 2002].

[3] An essential issue in data assimilation is the availability of data and its treatment. The oceanic observations, especially subsurface in situ observations, are still considered spatially sparse and temporally sporadic [McPhaden et $a l ., 1998]$. It will require considerable effort and computational expense to assimilate these sparse and sporadic data. The assimilation of this type of data therefore is often confined to a few national operational forecast centers or well-funded assimilation groups using specialized numerical models and assimilation algorithms. However, the demand for a good initial condition for individual models is common, and exists in many situations. The first example is seen in some theoretical studies such as physical process parameterization. The model's prediction skills are often used as a test bed to evaluate different parameterization schemes (e.g., 
comparing the model skill with and without the parameterization scheme). A second example arises from the study of climate predictability or reliability of the climate prediction. For these kinds of studies, we aren't particularly interested in elaborate methodologies or a highly competitive prediction skill because neither is the goal of these studies. However, we do wish the models used to have a useful and respectable prediction skill level since these studies need to be relevant for ENSO prediction. Therefore it is of interest to develop an initialization scheme that can avoid the complications of acquiring and processing raw in situ temperature observations, and the expenses on costly model integration. A possible solution is to apply a well-produced reanalysis product (such as the one use at the NCEP or the ECMWF) instead of raw in situ temperature observations. Compared with sparse and sporadic observations, reanalysis products are easier and more convenient to use, since they are usually regular gridded data sets. The high resolution of reanalysis products also allows us to use them for all types of oceanic models.

[4] Syu and Neelin [2000] simply inserted the NCEP reanalysis subsurface temperature into their OGCM, called as piggyback scheme, and found an improvement in ENSO prediction skill with the initialization scheme. However, in the work of Syu and Neelin [2000], OGCM and forcing fields were very similar to those used in the NCEP assimilation system. There are other situations where the model used for the assimilation system is rather different from that which is to be initialized, leading to an interesting question: whether a reanalysis product can be inserted into an oceanic model which is very different from that used in the assimilation system, and how detrimental is the inconsistency between them? In this paper, we will explore the problem via assimilating the NCEP reanalysis subsurface temperature [Behringer et al., 1998; referred to hereinafter as the NCEP data] into our OGCM. The NCEP used GFDL Modular Ocean Model (MOM2) for its assimilation system, which is rather different from our OGCM, and both models use different forcing fields, thus capable of demonstrating the generality of our technique. In addition, the NCEP reanalysis is promptly updated each month so that routine prediction using this product is possible.

[5] The other operationally significant issue in data assimilation is its computational expense. To further simplify our assimilation scheme, we will use an off-line strategy instead of the traditional scheme. The off-line strategy means that the initialization scheme no longer requires the ocean model's forward integration during the assimilation. The model restart files obtained from the control run are used as the first guess or background. This scheme will be referred to as the off-line 2D-Var scheme or off-line scheme throughout this paper.

[6] The paper is structured as follows: Section 2 briefly describes two hybrid coupled models and the initialization scheme in which a 2D-Var assimilation algorithm is applied. Section 3 examines the impact of the initialization scheme on ENSO prediction by a total 72 predictions from 19811998. The results presented in this section include prediction evaluations and ensemble statistics of skill. Section 4 explores the oceanic analysis of the off-line scheme in terms of the thermal and dynamical fields. A traditional 2D-Var assimilation is also performed in this section for comparison with the off-line scheme. Summary and discussion follow in section 5 .

\section{Coupled Models}

[7] Two hybrid coupled models (HCMs), an OGCM coupled to a statistical atmosphere (called HCM1 hereafter), and the same ocean model coupled to a dynamical atmospheric model of intermediate complexity (call HCM2 hereafter), were used to explore and test the initialization scheme. The different atmospheric components in the two HCMs allow us to examine the initialization scheme in a more general and universal framework. Below is a brief description for each component of the two coupled models.

\subsection{Ocean Model}

[8] The ocean model used is based on the OPA version 8.1 [Madec et al., 1999], a primitive equation OGCM. The turbulent closure hypothesis was used to parameterize subgrid-scale physical process, i.e., small-scale horizontal and vertical transports are evaluated in terms of diffusion coefficients and derivatives of the large-scale flow [Blanke and Delecluse, 1993]. The model uses an Arakawa $C$ grid layout, and was configured for the tropical Pacific ocean between $30^{\circ} \mathrm{N}-30^{\circ} \mathrm{S}$ and $120^{\circ} \mathrm{E}-75^{\circ} \mathrm{W}$. The horizontal resolution in the zonal direction is $1^{\circ}$, while the resolution in the meridional direction is $0.5^{\circ}$ within $5^{\circ}$ of the equator, smoothly increasing up to $2.0^{\circ}$ at $30^{\circ} \mathrm{N}$ and $30^{\circ} \mathrm{S}$. There were 25 vertical levels with 17 concentrated in the top $250 \mathrm{~m}$ of the ocean. The time step for integration was 1.5 hours. The boundaries were closed, with no slip conditions. The detailed formulation of this configuration of the ocean model is described by Vialard et al. [2002].

[9] The model was first spun up for 30 years with monthly observed climatological wind stress and heat flux $Q_{s}$ as forcing fields, where $Q_{s}$ was represented by climatological heat flux $Q_{0}$, obtained from the ECMWF reanalysis project, plus a relaxation term to $T_{0}$, the observed SST, i.e.

$$
Q_{s}=Q_{0}+\lambda\left(T-T_{0}\right),
$$

where $T$ is the model SST, $Q_{0}$ and $T_{0}$ are the monthly climatological heat flux and SST, respectively, and $\lambda$ (taken to be $-40 \mathrm{~W} \mathrm{~m}^{-2} \mathrm{~K}^{-1}$ ) controls the rate of relaxation to the observed SST. A similar annual mean net freshwater flux forcing was also used.

[10] After the 30-year spin up by the seasonal forcing, the model seasonal climatology was obtained. We then made a 50 -year model control run, by forcing with the NCEP reanalysis wind stress from 1951 to 2000 . The performance of the model is shown in Figure 1, showing that the ocean model produces a good simulation of tropical Pacific SSTA.

\subsection{Statistical Atmospheric Model}

[11] The Comprehensive Ocean-Atmospheric Data Set (COADS) [Smith et al., 1996] observed SST and the NCEP reanalysis wind data set were used to construct the atmospheric model. The time period taken for the model construction was from 1951 to 1980 . To remove high frequent noise and model drift, the NCEP wind was also detrended 

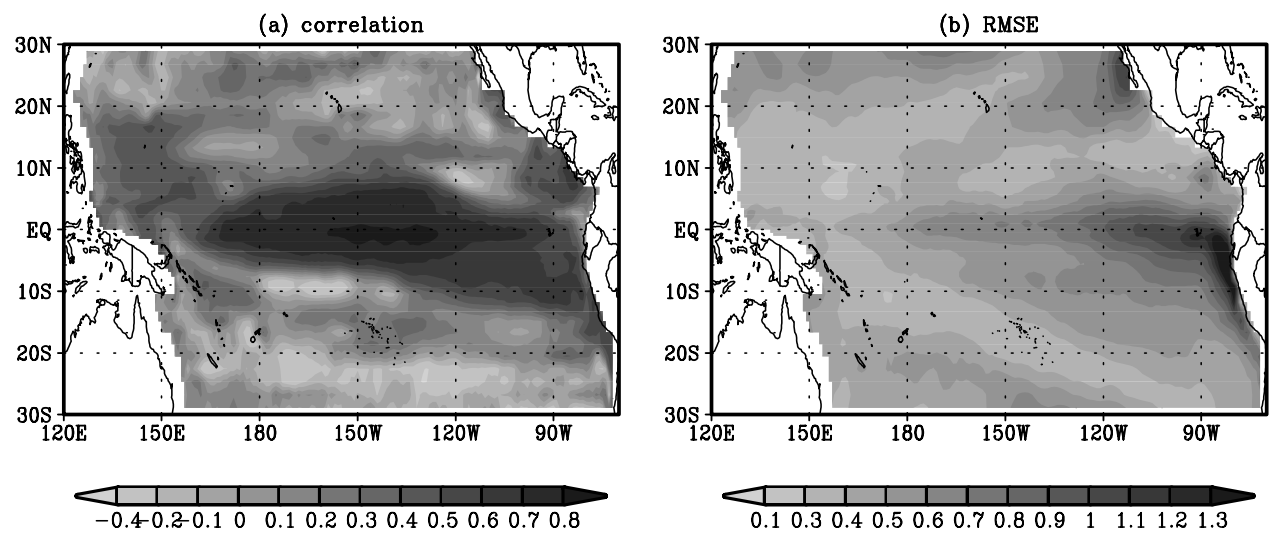

Figure 1. (a) Correlation and (b) RMSE between observed and modeled sea surface temperature (SST) anomalies derived from the control run forced with the National Centers for Environmental Prediction (NCEP) wind, from 1981 to 1999. See color version of this figure at back of this issue.

by a linear regression and smoothed with a 3-month running mean filter. The wind stress used to force the ocean model was computed from the detrended pseudostress as:

$$
\boldsymbol{\tau}=\mu \rho_{a} \mathbf{C}_{a}|\mathbf{U}| \mathbf{U}
$$

where $\mathbf{U}$ is the wind speed $(\mathrm{m} / \mathrm{s}), \rho_{a}=1.2 \mathrm{~kg} \mathrm{~m}^{-3}$ is the density of air, $C_{a}=0.0015$ is the drag coefficient and $\mu$ is a parameter controlling the strength of the forcing.

[12] Both SST and wind stress data were linearly interpolated onto the ocean model grid. An empirical orthogonal function (EOF) analysis was then employed on both data sets to extract the predictors and predictands. As by Barnett et al. [1993], the seasonal variations of the responses of windstress to SST were considered in the construction of the atmospheric model. A separate set of EOFs for each calendar month was thus used to construct a monthly varying atmosphere model.

[13] For a specified month, the predictor field $\operatorname{SST}(\mathbf{x}, t)$, and the predictand field $\tau(\mathbf{x}, t)$, the zonal or meridional component of the wind stress, can be expressed in terms of EOF modes $e_{n}(\mathbf{x})$, and $f_{n}(\mathbf{x})$

$$
S S T(\mathbf{x}, t)=\sum_{n} \alpha_{n}(t) e_{n}(\mathbf{x}) \quad \tau(\mathbf{x}, t)=\sum_{n} \beta_{n}(t) f_{n}(\mathbf{x})
$$

where $n$ is the EOF number, and $\alpha_{n}$ and $\beta_{n}$ are the corresponding time series of the EOF modes. The seasonal cycle had been removed for both fields prior to the EOF analysis.

[14] Table 1 shows the variance explained by the first 2 EOF modes for the variables used in the statistical atmospheric model. As shown in Table 1, for the SST, the first 2 EOF modes accounted for over $65 \%$ of total variance, whereas the variance contribution by individual modes became rather small after the first 2 modes (not shown). In contrast, the first 2 wind stress EOFs explained only about $40 \%$ of the total variance, due to presence of high frequency oscillations and noise in the wind stress field. The first two wind EOF modes, however, capture the main low frequency signals, e.g., ENSO (not shown), and are highly correlated with the observed SST anomaly averaged over the Niño3 $\left(150^{\circ} \mathrm{W}-90^{\circ} \mathrm{W}, 5^{\circ} \mathrm{N}-5^{\circ} \mathrm{S}\right)$ area. We also per- formed several sensitivity experiments, and found adding more EOF modes in fact degrades model predictive skills. Hence we used the first 2 EOF modes of SST as predictors, and the first 2 EOF modes of zonal or meridional wind stress as predictands, for constructing the atmospheric models.

[15] The linear regression model for a specified month is similar to that of Barnett et al. [1993]. The atmospheric model was trained with the data from 1951 to 1980. Therefore the prediction experiments carried out from 1981 to 1998 in the next section are completely independent of the construction of the atmospheric model. This strategy will remove the artificial skill in evaluating the prediction experiments.

\subsection{The Dynamical Atmospheric Model}

[16] The dynamical model consists of a Gill-type [Gill, 1980] steady state atmospheric model developed by Kleeman [1989, referred to hereinafter as Kleeman model]), and an atmospheric boundary layer (ABL) model developed by Kleeman and Power [1995]. They are both global anomaly models with the observed seasonal cycle of surface wind and observed mean atmospheric wind at $850 \mathrm{mb}$. The Kleeman model was coupled to the OGCM via the ABL model. The OGCM provides SST anomalies to the ABL model for computing the surface heat flux anomalies which were in turn imposed on the ocean model. On the other hand, the surface heat flux anomalies, and potential air

Table 1. Contributions of the First Two Principal Components in Percentages

\begin{tabular}{cccc}
\hline The Empirical Orthogonal Functions Mode & Obs. SST & $\tau_{x}$ & $\tau_{v}$ \\
\hline Jan. & 79.77 & 49.47 & 44.27 \\
Feb. & 70.25 & 44.59 & 48.38 \\
Mar. & 65.79 & 43.43 & 45.11 \\
Apr. & 65.03 & 40.87 & 38.34 \\
May & 71.36 & 38.52 & 33.50 \\
Jun. & 68.88 & 37.69 & 31.27 \\
Jun. & 72.62 & 41.56 & 37.30 \\
Aug. & 75.87 & 47.37 & 42.28 \\
Sep. & 77.50 & 51.56 & 41.85 \\
Oct. & 80.84 & 50.96 & 36.80 \\
Nov. & 81.75 & 48.72 & 36.44 \\
Dec. & 80.19 & 48.89 & 39.39 \\
\hline
\end{tabular}


temperature from the $\mathrm{ABL}$ model were passed to the Kleeman atmospheric model to generate the wind anomalies which then force the ocean. The intermediate complexity atmospheric model has been used for routine ENSO prediction and for the study of climate predictability. Complete details of the Kleeman model and the ABL model can be found in the work of Kleeman [1989] and Kleeman and Power [1995], respectively.

\subsection{Initialization Scheme}

[17] The assimilation method used here is a 2D-Var algorithm developed by Derber and Rosati [1989]. The NCEP reanalysis subsurface temperature will be assimilated into our OGCM using an off-line strategy as described in the introduction. The reanalysis subsurface temperature data set is a three-dimensional grid field of $1.5^{\circ}$ lat. by $1^{\circ}$ lon., and 27 standard depth levels between the surface and $3100 \mathrm{~m}$.

[18] Denoting the model's subsurface temperature by $\mathbf{T}^{b}$ which was saved in the restart files, and the NCEP reanalysis temperature by $\left(\mathbf{T}^{\mathbf{0}}\right)$, then a cost function can be defined as

$$
I=\frac{1}{2} \delta \mathbf{T}_{\mathbf{i}}^{\mathrm{T}} \mathbf{E}^{-1} \boldsymbol{\delta} \mathbf{T}_{\mathbf{i}}+\frac{1}{2}\left(\mathbf{D}\left(\delta \mathbf{T}_{\mathbf{i}}\right)-\delta \mathbf{T}_{\mathbf{i}}^{0}\right)^{\mathrm{T}} \mathbf{F}^{-1}\left(\mathbf{D}\left(\delta \mathbf{T}_{\mathbf{i}}\right)-\delta \mathbf{T}_{\mathbf{i}}^{0}\right)
$$

where $\delta \mathbf{T}_{\mathbf{i}}$ is the correction to the $i$ th layer model temperature $\mathbf{T}_{\mathbf{i}}^{b}$ contained in restart files, $\mathbf{E}$ is an estimate of error covariance matrix of $\mathbf{T}_{\mathbf{i}}^{b}, \delta \mathbf{T}_{\mathbf{i}}^{\mathbf{0}}$ is the difference between the 'observations' $\mathbf{T}_{\mathbf{i}}^{\mathbf{0}}$ and the interpolated $\mathbf{T}_{\mathbf{i}}^{b}, \mathbf{F}$ is the 'observed' error covariance of $\mathbf{T}^{\mathbf{0}}$, and $\mathbf{D}$ is a bilinear operator that interpolates from the model grid to the observation stations.

[19] The error covariance matrices $\mathbf{E}$ and $\mathbf{F}$ determine the spatial structure and amplitude of the correlation field. As by Derber and Rosati [1989], the horizontal covariances in $\mathbf{E}$ are defined to be approximately Gaussian, while vertical covariances are ignored. The horizontal covariance between any two points is approximately given by

$$
a e^{-r^{2} /\left(b^{2} \cos \phi\right)},
$$

where $\phi$ is the latitude of the grid point, $r$ the distance between any two points, $a=0.01\left({ }^{\circ} C\right)^{2}$, and $b=570 \mathrm{~km}$, as by Derber and Rosati [1989]. The function $I$ in equation (4) is minimized using a preconditioned conjugate gradient algorithm [Gill et al., 1981]. The preconditioning in the algorithm is supplied by the $\mathbf{E}$ matrix, which allows the solution to be found without directly inverting the $\mathbf{E}$ matrix. Further details about the algorithm can be found in the work of Derber and Rosati [1989] and Gill et al. [1981].

[20] As by Derber and Rosati [1989], the vertical correlation is ignored in the background error covariance matrix, the cost function $I$ is thus minimized in each layer independently. This strategy is also used in the ECMWF operational OI (optimal interpolation) scheme.

[21] For the observation error covariance matrix F, a common assumption is that the observational errors are uncorrelated; i.e., that the matrix $\mathbf{F}$ is diagonal. However, the 'observations' used here are actually from a reanalysis, suggesting that the 'observational' errors are probably spatially correlated. In this case, the assumption that the matrix $\mathbf{F}$ is diagonal is not correct and could lead to an overweighting of the 'observations' in the optimization. In principle, the problem can be solved by a nondiagonal matrix for F, although this would greatly increase the complexity of the algorithm for solving equation (4). To avoid the complications of defining the inverse of a nondiagonal matrix $\mathbf{F}$, we adopt a simpler strategy of thinning the reanalysis 'observations' used in (4), and hence reducing the effects of correlated observation errors. To achieve this, we discard 'data' at grid points on even-order latitudes. The observation error variances are set to $\left(0.5^{\circ} \mathrm{C}\right)^{2}$ in this study.

[22] $\delta \mathbf{T}_{\mathbf{i}}^{a}$ can be obtained by minimizing $I$ of (4) using a preconditioned conjugate gradient algorithm [Derber and Rosati, 1989], where $a$ denotes the analysis. The $i$ th layer corrected temperature is thus simply written $\mathbf{T}_{\mathbf{i}}^{a}=\mathbf{T}_{\mathbf{i}}^{b}+\delta \mathbf{T}_{\mathbf{i}}^{a}$. In this procedure, the ocean model is not directly involved in the optimization process except that it provides the model temperature $\mathbf{T}_{\mathbf{i}}^{b}$ by restart files. In this study, the temperatures of the upper 17 layers of the ocean model were analyzed (i.e., $\mathrm{i}=1,2,3$...17). The domain over which (4) was minimized is the tropical Pacific, $15^{\circ} \mathrm{S}-15^{\circ} \mathrm{N}$.

\section{EI Niño-Southern Oscillation (ENSO) Prediction}

[23] Next we examine the predictions by the two HCMs described above. Two initialization schemes, one from the control run (simply forced with the NCEP wind stress), the other one from the off-line scheme, were used. A total of 72 predictions were made for each experiment from January 1981 to December 1998, starting at three months intervals (1 January, 1 April, 1 July, 1 October), and continued for 12 months.

[24] Figures 2a and 2c show correlation skills of the predictions initialized by the control run and the off-line scheme, where the predicted Niño3 SSTA is compared against the observed values. Compared with the persistence skill, the predictions initialized by the off-line scheme beat persistence from the second month for both models whereas the predictions initialized from the control run beat persistence from the fourth month for HCM1 and the seventh month for HCM2. For HCM2 (Figure 2a), the prediction skills rapidly decline with lead time, reaching a minimum at 8 months, beyond which the skill rebounds and increases till a lead time of 12 months, in contrast to the predictive skills of HCM1 (Figure 2c), which simply decline with lead time in the first 8 months, and then stabilize till the end. However, with initialization by the off-line scheme, there is an obvious improvement in the performance of both models in correlation skills for all lead times, in particular for lead times over 4-6 months. Likewise, there are also some improvements in root mean square error (RMSE) for the predictions initialized by the off-line scheme (Figures $2 b$ and $2 \mathrm{~d}$ ), in particular for the lead times of $>5-6$ months. The off-line scheme also improved the prediction skills of Niño3.4 SSTA $\left(170^{\circ} \mathrm{W}-120^{\circ} \mathrm{W}, 5^{\circ} \mathrm{N}-5^{\circ} \mathrm{S}\right)$ for all lead times for HCM1 and HCM2 (not shown).

[25] Figure 2 was obtained from 72 predictions. The finite sample size implies some uncertainty in the computed correlation coefficient and RMSE. To determine the extent of this uncertainty we used the bootstrap method of sample point omissions. For each lead time, a data pair of predictions and observations was constructed. Such a 
(a) $\mathrm{HCM} 2$

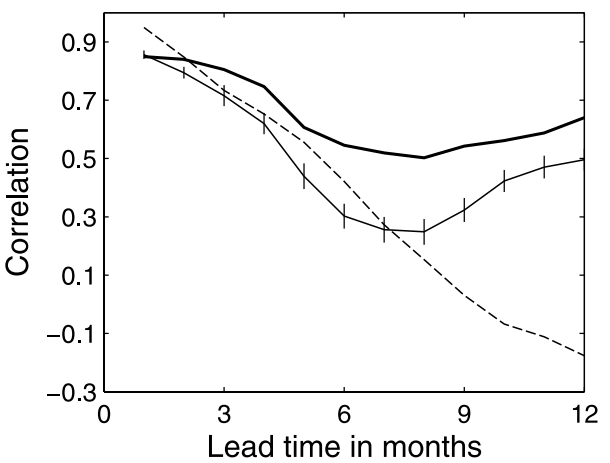

(b) HCM2

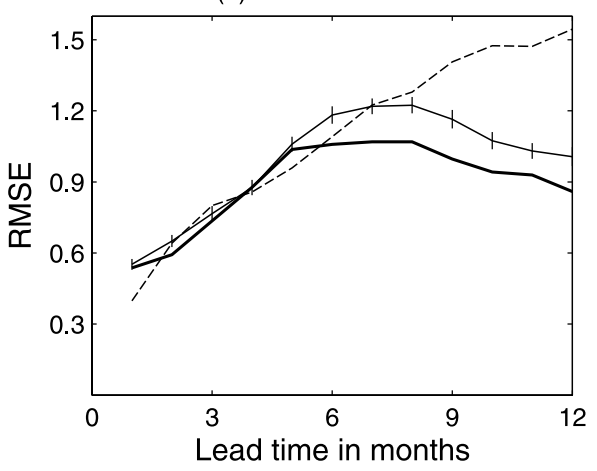

(c) HCM1

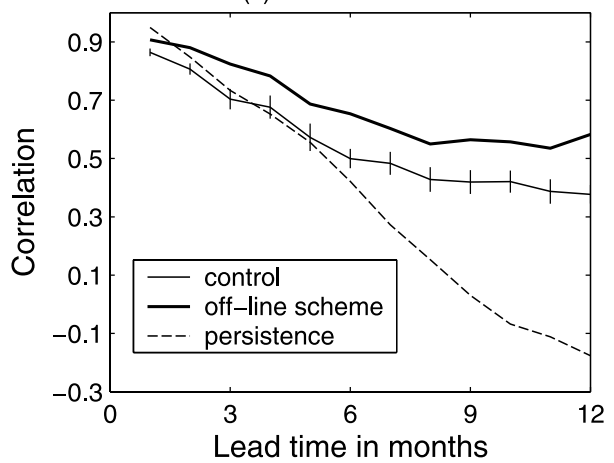

(d) HCM1

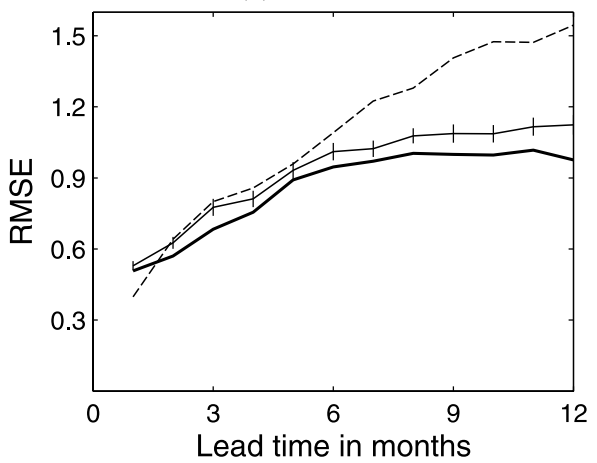

Figure 2. (a, c) Correlation and (b, d) RMSE between observed and predicted SST anomalies in the Niño3 region, as a function of lead time. The predictions are initialized every 3 months from January 1981 to December 1998. Thick line is from the prediction initialized from the off-line scheme. Thin line is from the prediction initialized from the control run. Error bars from bootstrapping are also shown as the short line overlapped in the thin line. HCM2 (left) and HCM1 (right).

pair was then divided into equal-in-length blocks each containing data corresponding to a certain period of time. The division was randomly altered by changing the division starting point. Many additional samples were constructed using the moving blocks bootstrap sampling [Efron and Tibshirani, 1993]. Correlation and RMSE of each sample were calculated, and an ensemble of correlation and RMSE can therefore be obtained respectively. The standard deviation $\sigma$ of the ensemble was used to measure the uncertainty of the correlation or RMSE.

[26] The uncertainty estimations $(+\sigma$ and $-\sigma)$ superimposed on the original skills are displayed in Figure 2 (short line). Clearly, the increase in the correlation skills at all lead times results from the improvement in the initial conditions due to the off-line scheme, rather than from the uncertainty of the finite sample size. This is a little different from the contribution of the off-line scheme to RMSE skills, which was mainly performed on the predictions of lead time over 5 months.

[27] Figure 3 shows the SSTA predicted by HCM1 at a lead time of 9 months using the two initialization schemes. Generally it was found that the initialization from the offline scheme leads to better predictions of ENSO warm events, particularly in the strength and phase prediction. There are some spurious phase precedences and relatively weak amplitude in El Niño predictions initialized by the control run, i.e., the predicted warming being earlier and weaker than observations. For example, the 1987/1988 and 1991/1992 warm events were predicted around 1 year earlier than the observations in Figure 3a. The spurious phase precedences also occurred at the predictions of other lead times and in HCM2 (not shown). However, some of the deficiencies could be alleviated in the predictions initialized by the off-line scheme as shown in Figure 3c, probably due to the off-line scheme leading to a more realistic initial thermal field (see next section).

[28] It should be noted that the off-line scheme led to a poor prediction of 1988-1989 cold event. Compared with observation and the prediction by control run, the prediction by the off-line scheme delayed the cooling about one year. This is due mainly to the assimilation of the thermal field generating an unfavored condition for the cold event. An "on-line" scheme (2D-Var) [Derber and Rosati, 1989] also shows the same delay in the prediction (not shown).

[29] Shown in Figures 4 and 5 are the predictions for two typical ENSO events, the 1982/83 and 1997 El Niño, in which HCMs and both initialization schemes were used. Compared with the observed SSTA, all experiments predict the anomalous warming in the equatorial Pacific, but most predictions suffered an unrealistically early decay. The predicted warming strength also was weaker than the observation. Some of these deficiencies are alleviated by the off-line scheme however.

[30] The advantage of the off-line scheme could be further demonstrated by the prediction of the 1987 El Niño event in that the model intrinsic damping has less impact on the prediction of the weak anomalous warming. Figure 6 shows the predicted SSTA along the equator, indicating that 


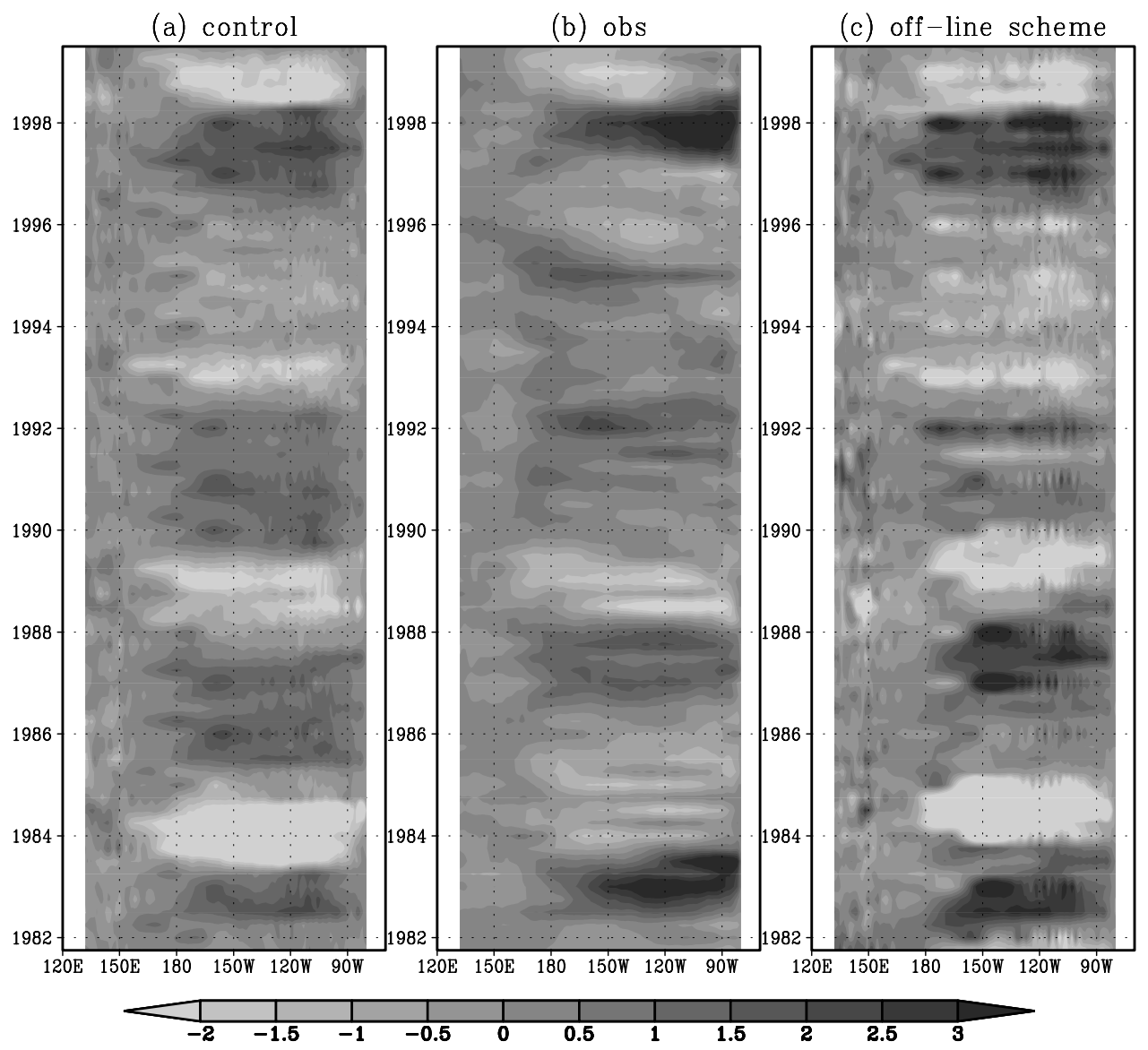

Figure 3. Time-longitude diagrams of predicted sea surface temperature anomaly (SSTA) with HCM1 along the equator at the lead time of 9 months, initialized by the (a) control run and by (c) the off-line scheme. For comparison, (b) the observed SSTA is shown. See color version of this figure at back of this issue.

the off-line scheme generated a much better prediction than the control run for both HCMs. This is likely due mainly to the fact that the off-line scheme leads to a more realistic simulation of subsurface heat content anomalies both in terms of the intensity and the eastward propagation (see Figure 9).

\section{Analysis of Initial Field}

[31] Using two coupled models and hindcast experiments, we have presented evidence that the new initialization scheme can yield significant improvement in ENSO prediction skill. In this section, we will further explore the offline scheme by examining its impact on the initial fields of the prediction.

\subsection{Thermal Fields}

[32] We first examine the thermal structure of the initial fields. Shown in Figure 7 are the correlations between the observed temperature anomalies and the modeled temperature anomalies at the surface, and at the depth of $60 \mathrm{~m}$ and $120 \mathrm{~m}$ during 1981-1998. The modeled temperature anomalies were derived from the restart files generated by either the control experiment or the off-line scheme. The observed SST is from COADS with $2^{\circ}$ lat by $2^{\circ}$ long. The observed subsurface temperatures are from the data set of the Joint Environmental Data Analysis Center at the Scripps Institution of Oceanography. This data set consists of all available XBT, CTD, MBT and hydrographic observations, optimally interpolated by White [1995] to a three-dimensional grid of $2^{\circ}$ lat. by $5^{\circ}$ lon., and 11 standard depth levels between the surface and $400 \mathrm{~m}$. As can be seen in Figure 7, the off-line scheme has the best simulation for the SSTA, and then for temperature anomalies at $60 \mathrm{~m}$ and $120 \mathrm{~m}$. The improvement in the simulation of subsurface temperature anomalies mainly occurs in the equatorial Pacific, especially in the western Pacific. The RMSE between the observation and model also exhibited similar features (not shown).

[33] It has been well documented that the variations of subsurface temperature in the equatorial western Pacific play a crucial role in ENSO evolution, explaining perhaps why the off-line scheme can lead to better predictions. Further evidence that the off-line scheme generates a better simulation for the thermal field along the equatorial Pacific can also be found in Figure 8, which shows the correlation and RMSE of the top $250 \mathrm{~m}$-depth-averaged heat content anomalies (Heat content is defined here as the integral of the temperatures over the top $250 \mathrm{~m}$, calculated from $H C=\frac{\Sigma h_{i} T_{i}}{\Sigma h_{i}}$ where $h_{i}$ and $T_{i}$ are respectively the thickness and temperature of level $i$.) between model and observation. 


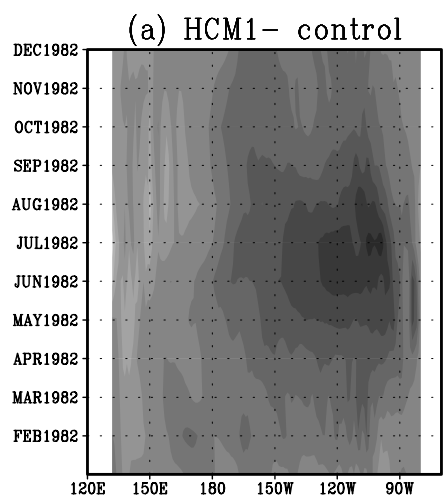

(b) HCM1- off-line scheme

(c) observation
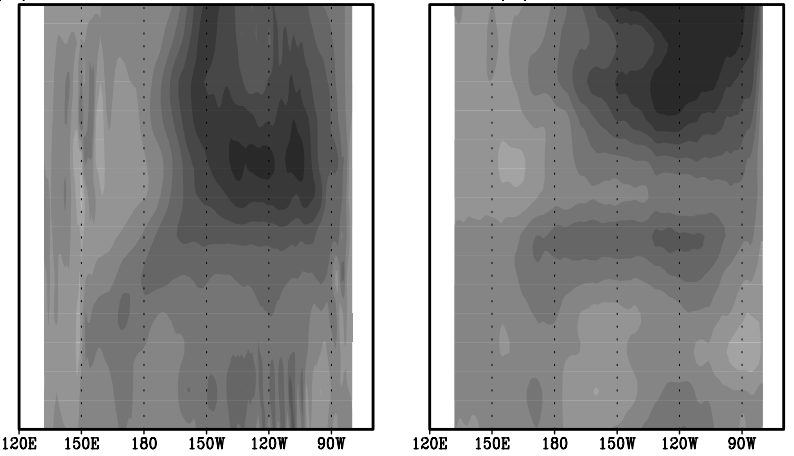

(d) HCM2 - control

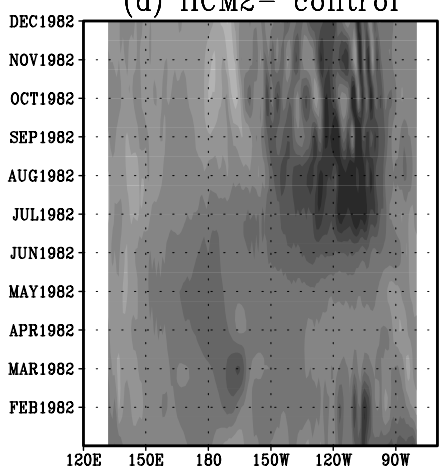

(e) HCM2- off-line scheme
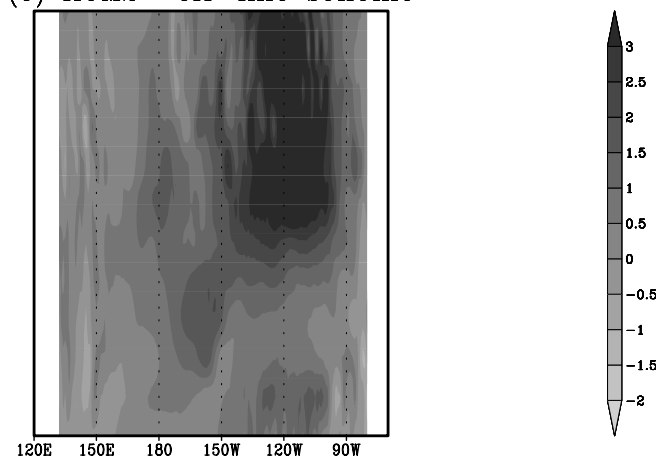

Figure 4. Time-longitude diagrams of predicted SSTA along the equator for the 1982/83 warm event. The predictions were carried out with the two hybrid coupled models (HCMs), initialized by the control run and the off-line scheme, on 1 January 1982. For comparison, the observed SSTA is shown. See color version of this figure at back of this issue.

[34] The physical basis for ENSO prediction is that a delayed oscillation exists between the equatorial western Pacific and the equatorial eastern Pacific which has been demonstrated by many studies [e.g., Schopf and Suare, 1988; Battisti, 1988]. The delayed oscillation can be characterized by a phase shift of the variations of upper ocean heat content anomalies (HCA) between the western Pacific and the eastern Pacific, with the variations in the west leading those in the east. This phase-shift relation can be explored via a Hovmöller diagrams of upper ocean heat content anomalies along the equator as shown in Figure 9. As can be seen, the HCA has a more realistic feature of eastward propagation in the off-line scheme (Figure 9b) than in the control experiment (Figure 9a) when compared with the observation (Figure 9c). This is especially obvious in some moderate El Niño events such as in 1986/87 and in the early 1990s events. The lag correlation of $\mathrm{HCA}$ between the west (Niño4, $160^{\circ} \mathrm{E}-$ $150^{\circ} \mathrm{W}, 5^{\circ} \mathrm{N}-5^{\circ} \mathrm{S}$ ) and the east (Niño3) in the two initialization schemes also showed that the off-line scheme indeed led to a better east-west delayed relation than the control run. For example, while Niño3 SSTA lagged Niño4 SSTA by 9 months, the correlation coefficient was 0.42 for the off-line scheme compared with a correlation 0.30 for the control experiment.

[35] Shown in Figure 10 are SSTA simulation against observation, indicating that the off-line scheme has a better skill, in particular for the simulation of amplitude for strong El niño events such as 1983 and 1997.

\subsection{Dynamical Fields}

[36] As discussed above, a more realistic thermal structure in the prediction initial field, characterized by a more realistic eastward propagation of upper ocean heat content anomalies, can be obtained by the off-line scheme. The feature of the eastward propagation of HCA is reminiscent of the delayed action oscillator mechanism. The capability of better characterizing the delayed action oscillator mechanism in the offline scheme might be a major reason why the off-line scheme leads to a considerable improvement in ENSO predictions.

[37] One issue of potential concern in the off-line scheme is possible imbalances between the dynamical and thermal fields, since there is no adjustment and correction in the dynamical variables to response to the correction in the subsurface temperature. Theoretically, such imbalances could degrade the model prediction skill. However, the ensemble predictions discussed above show good skill in the off-line case, suggesting that the imbalances are likely to be very small or unimportant to prediction. On the other hand, the imbalances may be able to be adjusted quickly through geostrophic balance in the coupling (prediction) run. To further explore this, we performed a traditional 2D-Var assimilation experiment with the same 'observations'. A traditional 2D-Var assimilation usually consists of the following steps: 
(a) HCM1- control

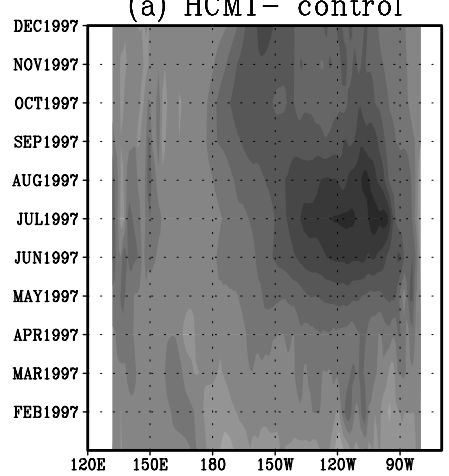

(d) HCM2- control

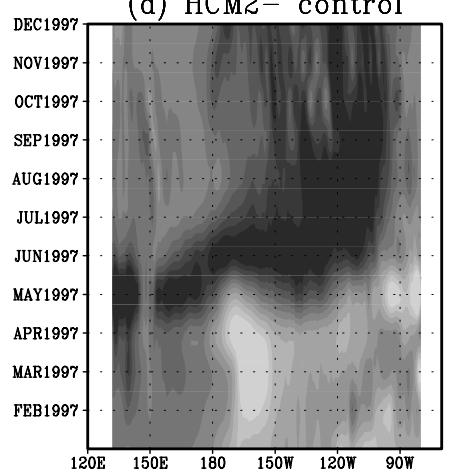

(b) HCM1- off-line scheme

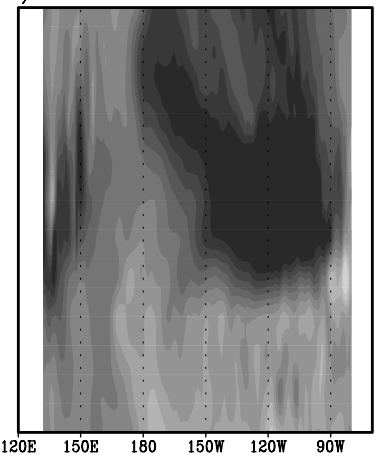

(c) observation

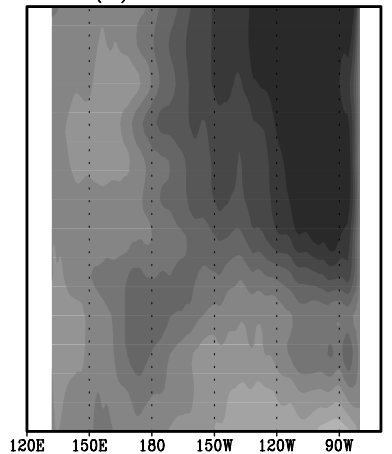

(e) HCM2- off-line scheme

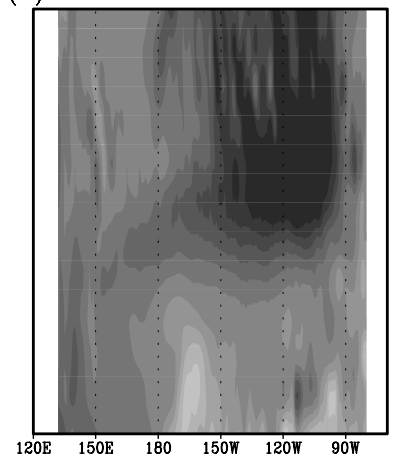

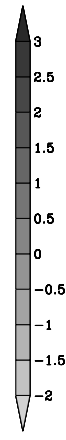

Figure 5. Same as in Figure 4 but for the 1997 warm event. The prediction was initialized on 1 January 1997. See color version of this figure at back of this issue.

(a) HCM1- control

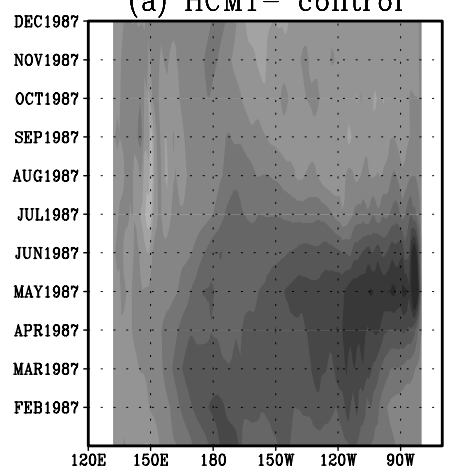

(d) HCM2- control

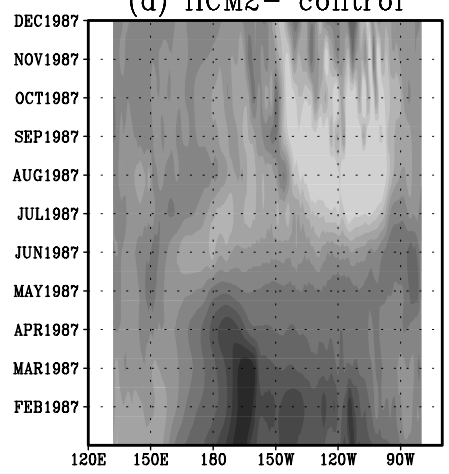

(b) HCM1- off-line scheme

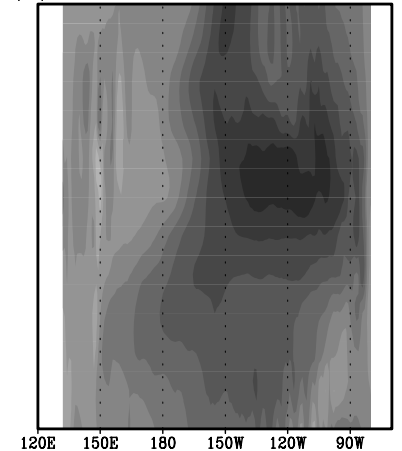

(c) observation

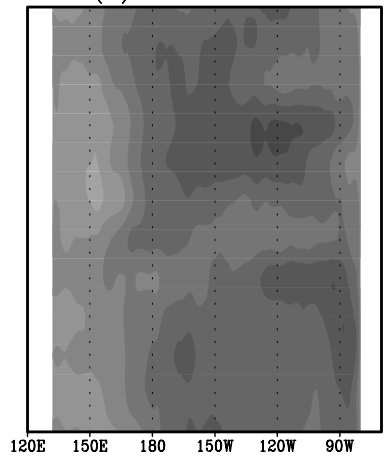

(e) HCM2- off-line scheme

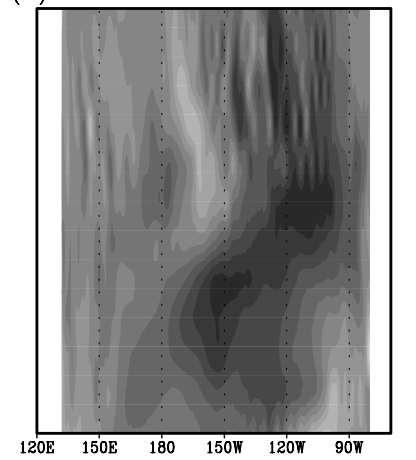

Figure 6. Same as in Figure 4 but for the 1987 warm event. The prediction was initialized on 1 January 1987. See color version of this figure at back of this issue. 


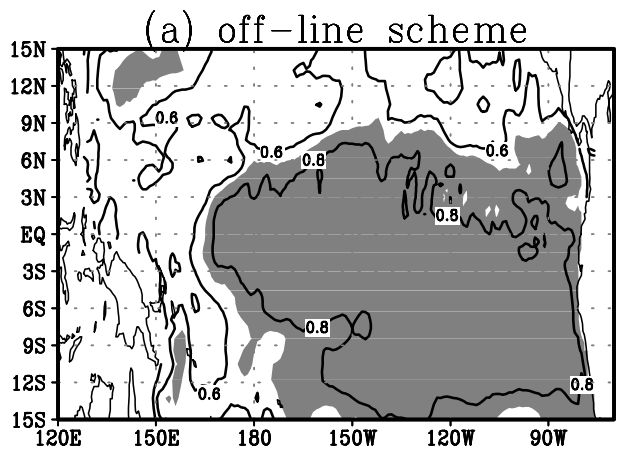

(c) off-line scheme
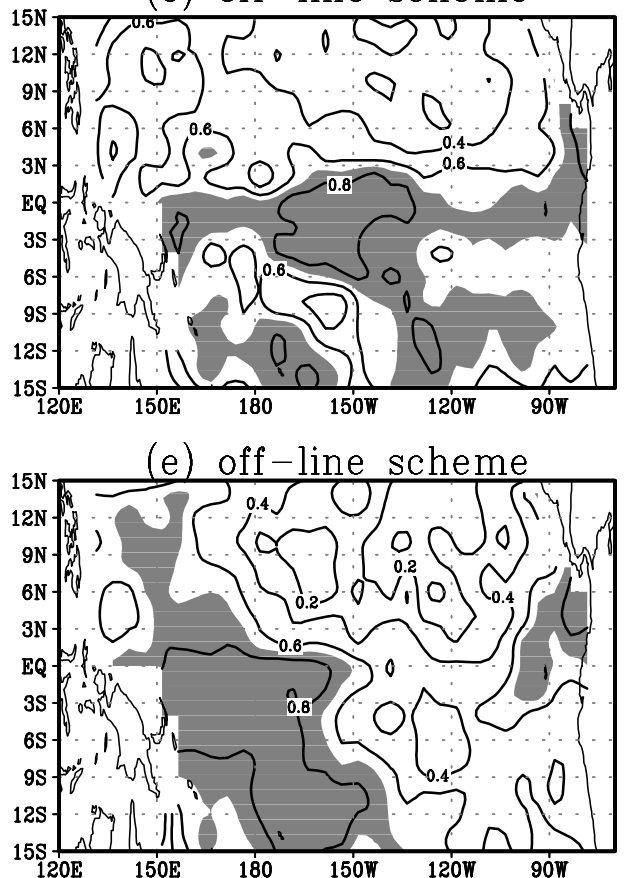

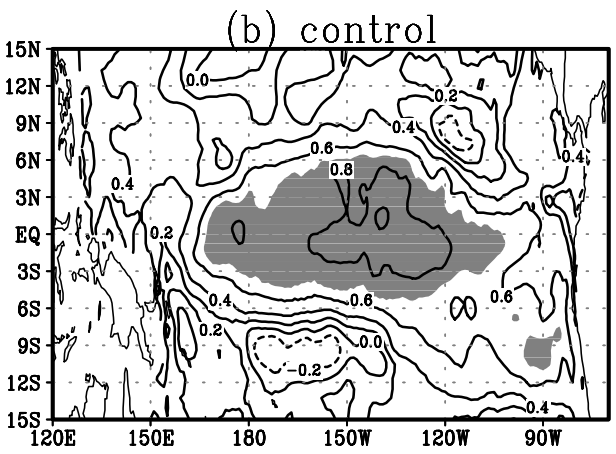

(d) control
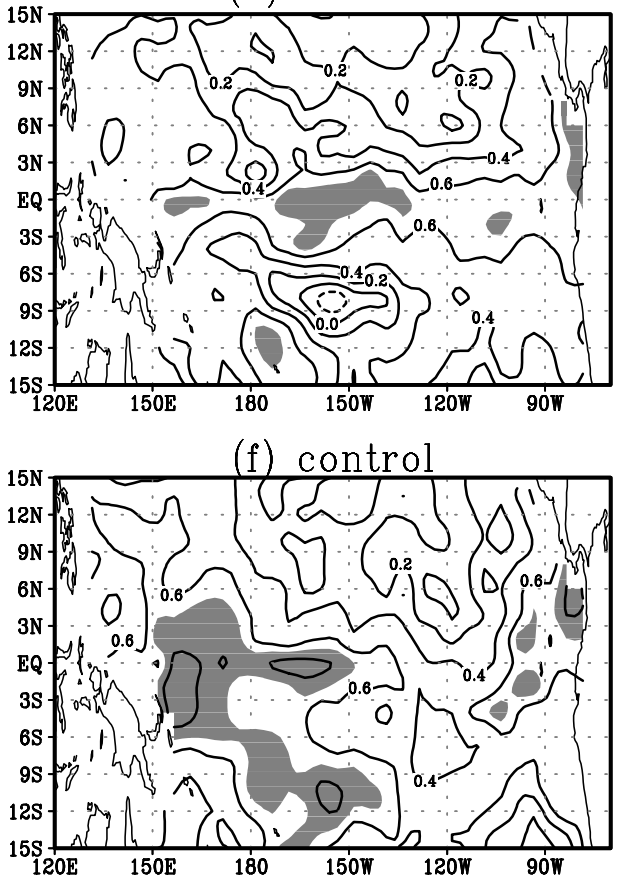

Figure 7. Correlations of modeled temperature anomalies from the control run and the off-line scheme at the surface (top), at $60 \mathrm{~m}$ depth (middle) and $120 \mathrm{~m}$ depth (bottom) relative to the observed counterparts during January 1981-December 1998. The areas with correlation over 0.7 are shaded.

(1) producing oceanic analyses at $\mathrm{t}=t_{i}$ for the variables assimilated using equations (4) and (2) integrating the ocean model forward one step using the oceanic analyses as new initial conditions. (3) repeating (1) and (2) until a period of time (called the assimilation window) is performed. The difference between a traditional 2D-Var and the off-line scheme is that during the latter, step (2) is omitted. In the traditional scheme, all model variables are updated at each step so that the imbalance of model physical fields in the assimilation could be well alleviated by the model's instantaneous adjustment. As such, examining the differences of dynamical fields between the off-line scheme and the traditional assimilation allows us to identify the nature of the imbalances caused by the off-line scheme.

[38] We performed the traditional 2D-Var for 2 years. The start time was randomly chosen in 1993. The assimilation interval is 3 days, i.e., the observations were inserted into the model once every 3 days. We arbitrarily choose the surface zonal current as our object of examination.

[39] Shown in Figure 11 are two zonal current fields at three different times, respectively obtained from the off-line scheme and the traditional assimilation scheme. At the end of 1 month, the two fields are almost identical with a spatial correlation of 0.99 . As the time increases, the influence of model adjustment on the zonal current can be clearly seen along the equator, the traditional assimilation scheme generating stronger equator current in the eastern Pacific. However, the differences between the two schemes are not very large. For example, the spatial correlation between the two schemes is still up to 0.86 and 0.83 at $\mathrm{t}=12$ and $\mathrm{t}=24$. Figure 11 suggests that the imbalance that exists between thermal and dynamical fields in the off-line scheme is relatively small. Such a relatively small imbalance could be quickly adjusted in the prediction run, and may have little impact on the forecast. Figure 12 shows the evolution of $u$ in a forecast initialized by the off-line scheme and by the traditional assimilation scheme. As can be seen, the difference of $u$ between the two schemes quickly decreases as the forecast integration increases. At the end of the 6 months, the structure of $u$ from the off-line scheme has adjusted to a pattern similar to that from the traditional assimilation scheme. Table 2 further demonstrates the 


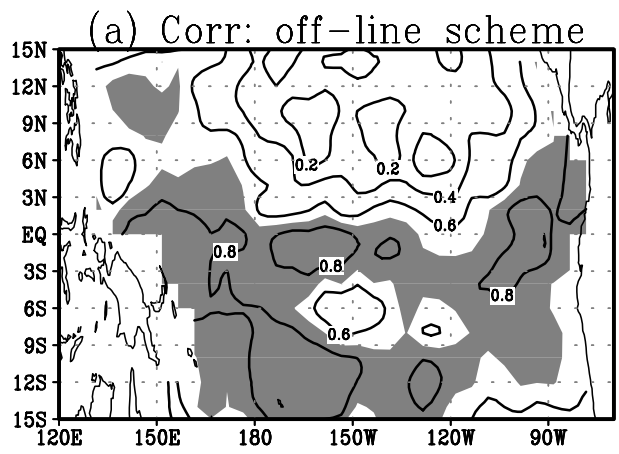

(c) RMSE: off-line scheme

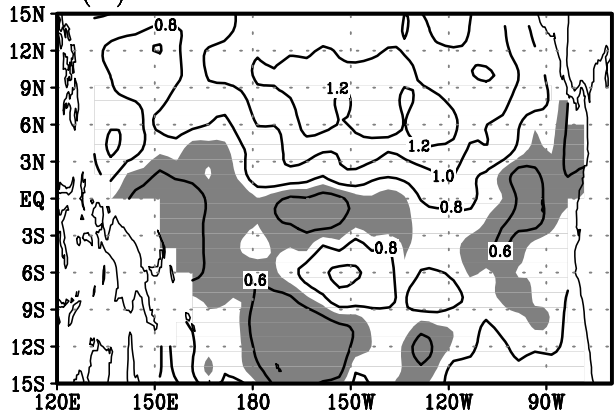

(b) Corr: control

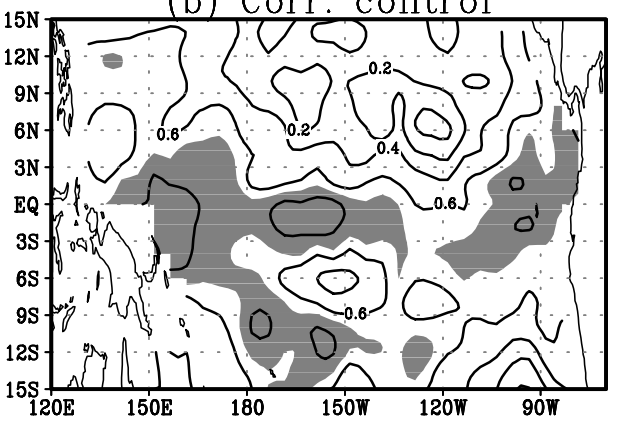

(d) RMSE: control

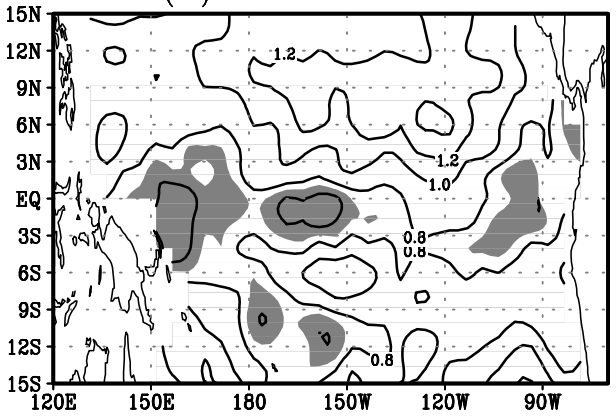

Figure 8. Correlations (a, b) and RMSE (c, d) of modeled HCA from the control experiment and the off-line scheme relative to the observed HCA during January 1981-December 1998. The areas with correlation over 0.7 and $\mathrm{RMSE}<0.7^{\circ} \mathrm{C}$ are shaded.

(a) control

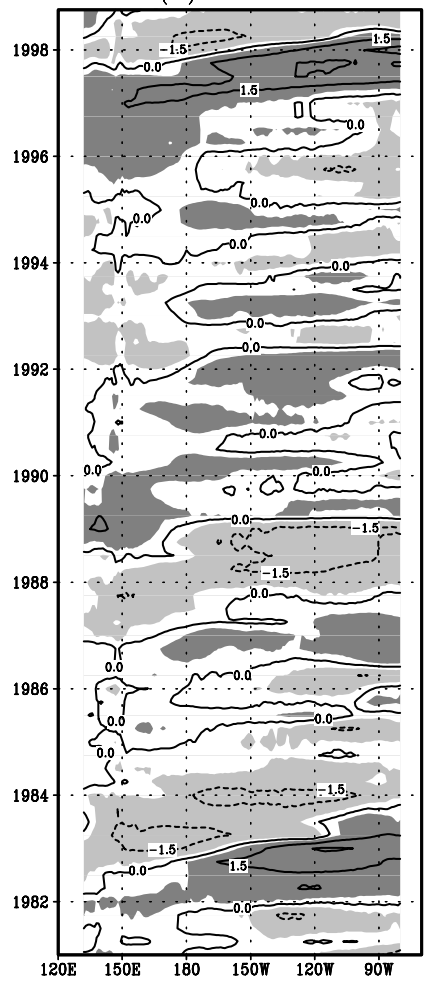

(b) off-line scheme

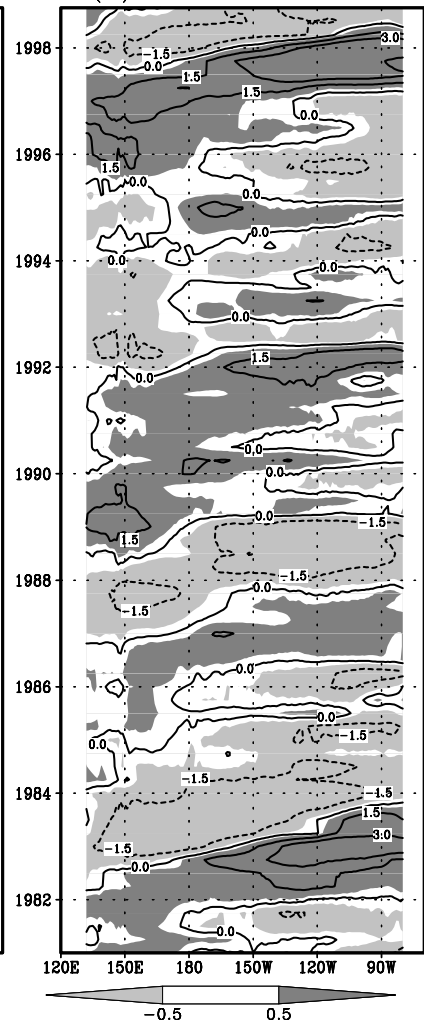

(c) obs.

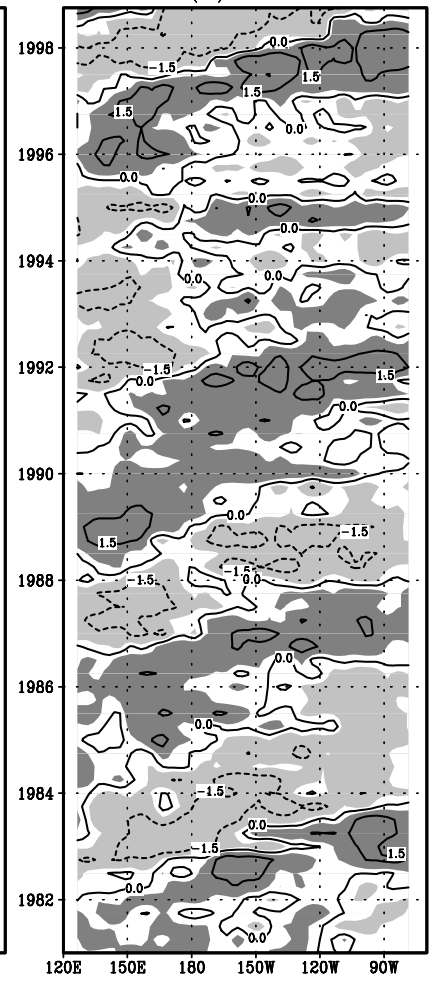

Figure 9. Time-longitude plots of the HCA along the equator during 1981-1998 from (a) the control experiment, (b) the off-line scheme, and (c) the observations. Contour interval is $1.5^{\circ} \mathrm{C}$ and the absolute values above $0.5^{\circ} \mathrm{C}$ are shaded. 
(a) control

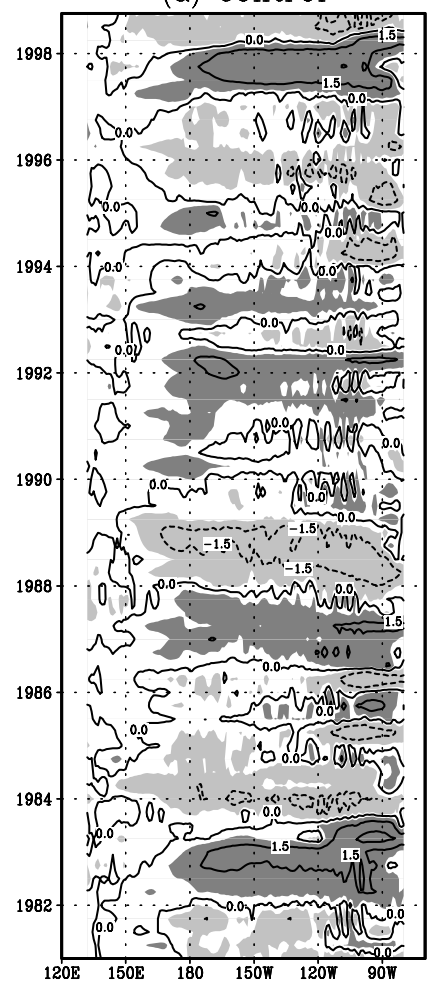

(b) off-line scheme

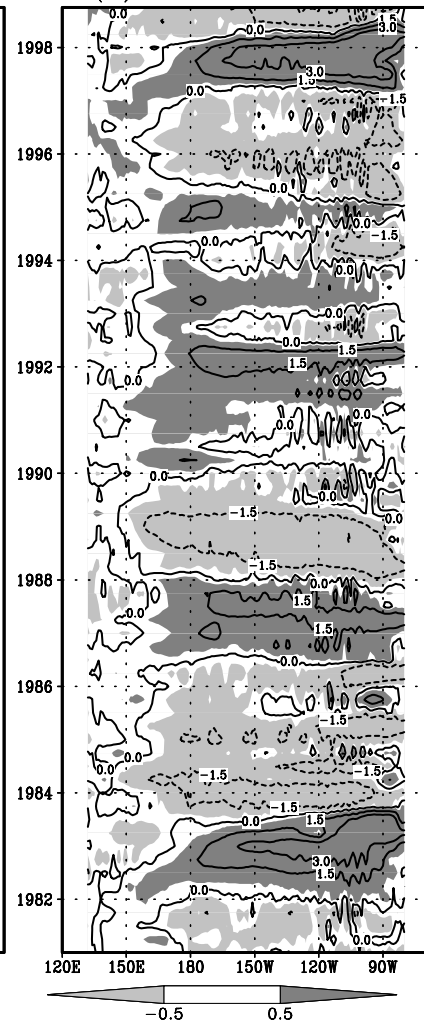

(c) obs.

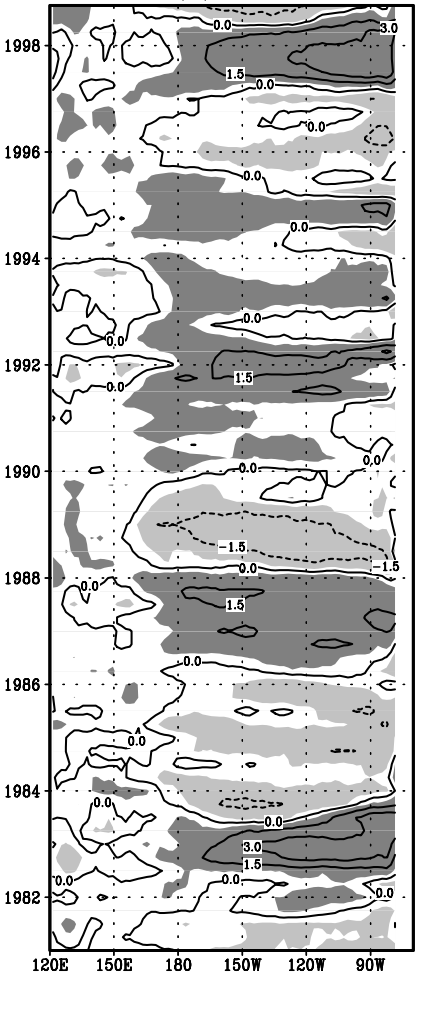

Figure 10. Same as Figure 9 but for SSTA. Contour interval is $1.5^{\circ} \mathrm{C}$ and the absolute values above $0.5^{\circ} \mathrm{C}$ are shaded.

adjustment process, where the relative sum of error squared (RSES) is defined as

$$
R S E S=\frac{\left(\mathbf{u}^{1}(t)-\mathbf{u}^{2}(t)\right)^{t r}\left(\mathbf{u}^{1}(t)-\mathbf{u}^{2}(t)\right)}{\mathbf{u}^{2}(f t)^{t r} \mathbf{u}^{2}(t)}
$$

$\mathbf{u}^{1}(t)$ and $\mathbf{u}^{2}(t)$ are the zonal current, respectively generated by the off-line scheme and the traditional assimilation scheme. RSES depicts the relative differences of two fields, i.e., the portion of the differences explained by the $\mathbf{u}^{2}$ variances. Also shown in Table 2 are the correlations between $\mathbf{u}^{1}(t)$ and $\mathbf{u}^{2}(t)$ at different times.

[40] It is worth noting that a traditional scheme could also lead to imbalances since the dynamics of models is sometimes not enough to get rid of the imbalances, as reported by some work [e.g, Burgers et al., 2002; Troccoli and Haines, 1999]. A typical example is a systematic error in the wind stress, leading to large errors in zonal currents. In this sense, a traditional scheme might not be necessarily more "in balance" than the off-line scheme. However, Vialard et al. [2002] and Weaver et al. [2003] found that the traditional scheme can lead to a good adjustment of currents for the OGCM.

\section{Discussion and Summary}

[41] Generally, there are two practical problems afflicting the initialization of an OGCM for ENSO prediction; one is the complications of acquiring and processing raw in situ temperature observations, and the other is the relatively expensive computational cost. The practical problems may cause unnecessary difficulties for many ENSO researchers. In particular those without the interest and sufficient computational resource for working on data assimilation will be adversely impacted. To alleviate these problems, we have proposed an off-line scheme. In this scheme, the NCEP reanalysis temperature was used instead of in situ subsurface temperature, and then a traditional 2D-Var assimilation algorithm is simplified by omitting the original model forward integration during the assimilation cycle. With two quite different but realistic hybrid coupled models, we tested and validated the off-line scheme using a total of 72 predictions from 1981 to 1998 . The prediction statistics show convincingly that our ENSO forecasting models initialized using the off-line scheme have predictive skill for Niño3 SSTA which is significantly improved over a windstress forced only initialization technique. The effect is most noticable for lead times longer than 4-6 months. The predictive skill from the off-line scheme is about the same as that from a traditional 2D-Var assimilation algorithm. This implies that researchers of ENSO predictability who wish to use accurate analyses may not need to bother with the complication of processing raw data and the costly expense of traditional assimilation algorithms which use forward integration steps of the ocean model.

[42] To shed some light on the off-line scheme, we analyzed the initial fields generated by the off-line scheme. It was found that compared to the control run, the off-line scheme generated a better simulation for thermal fields along the equatorial Pacific. Consequently, the thermal fields were better characterized by the delayed action oscillator mechanism, leading to better predictive skills. 
(a) $t=1$

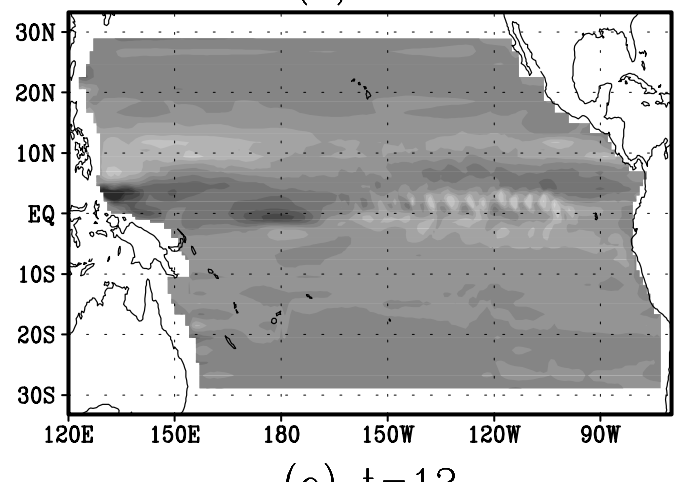

(c) $t=12$

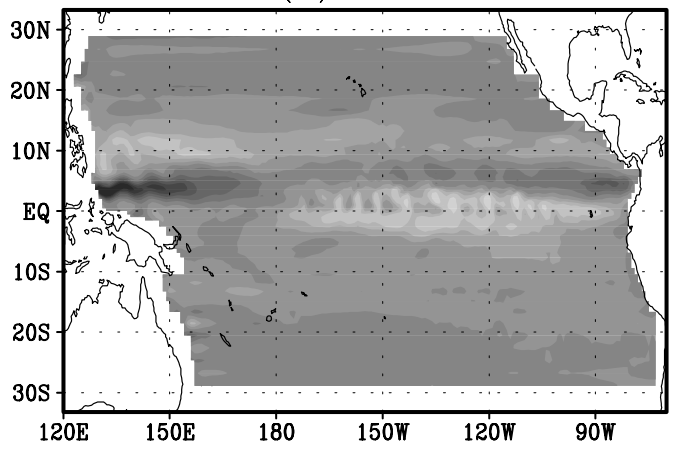

(e) $t=24$
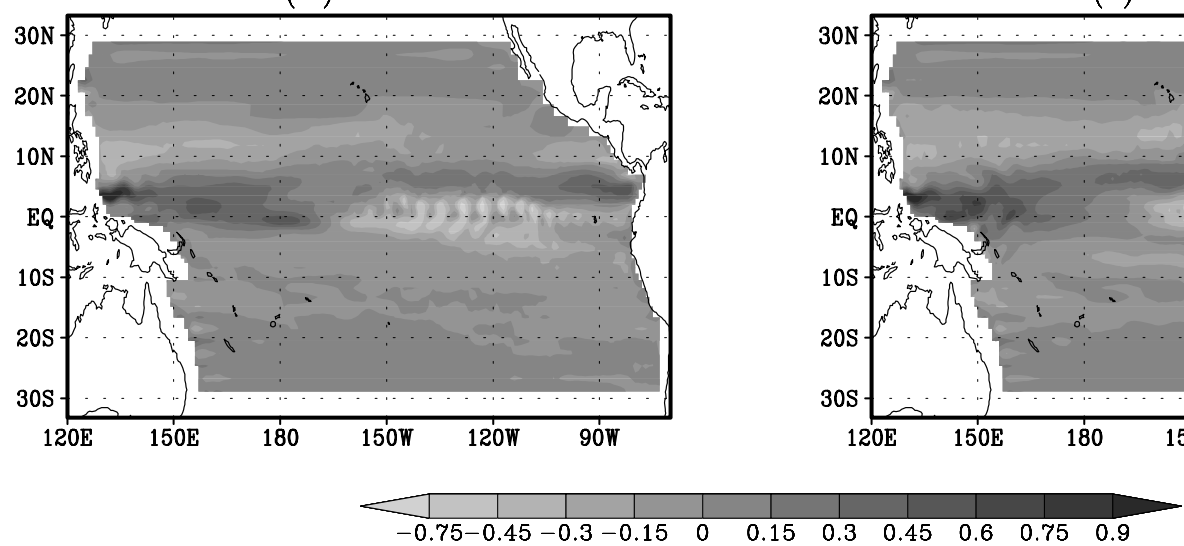

Figure 11. The velocity of the surface zonal current $(u)$ from the off-line scheme (left) and traditional assimilation scheme (right) at three different times. See color version of this figure at back of this issue. (b) $t=1$

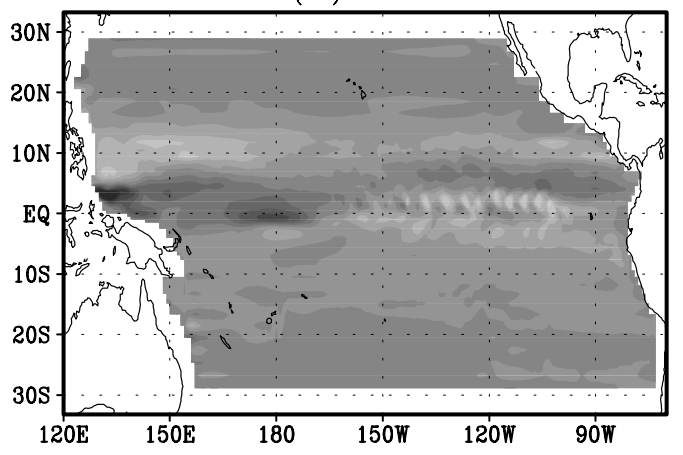

(d) $t=12$

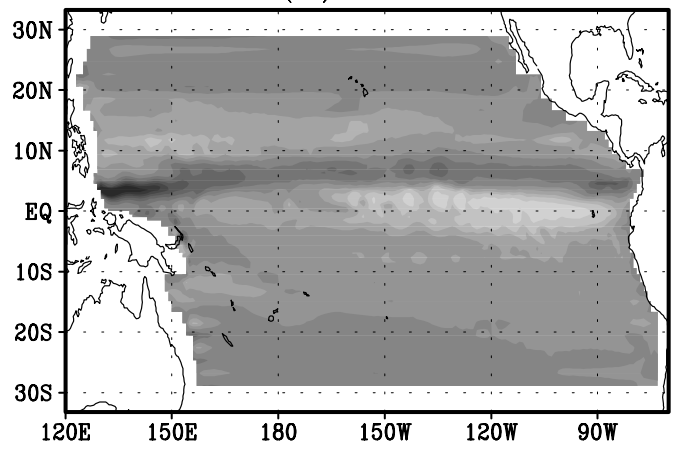

(f) $t=24$
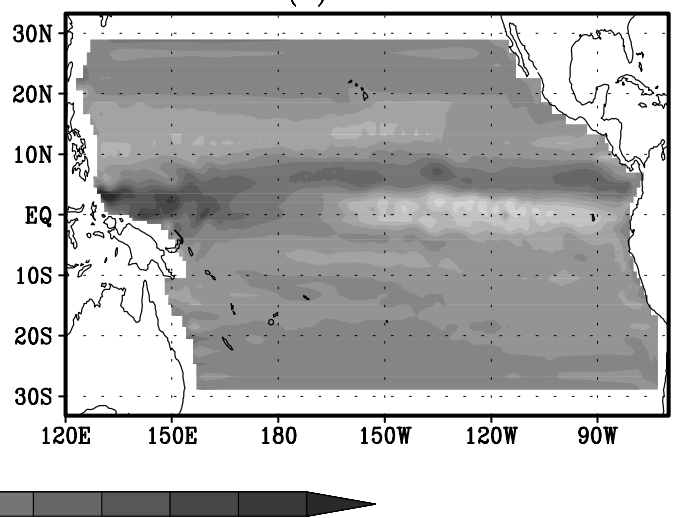

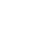


(a) $t=1$

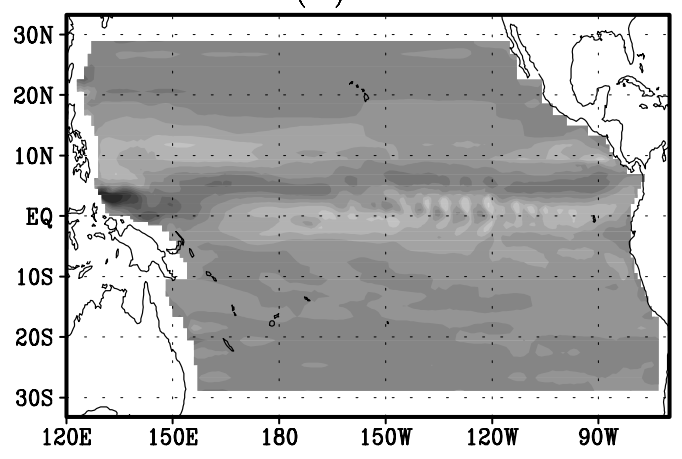

(c) $\mathrm{t}=3$

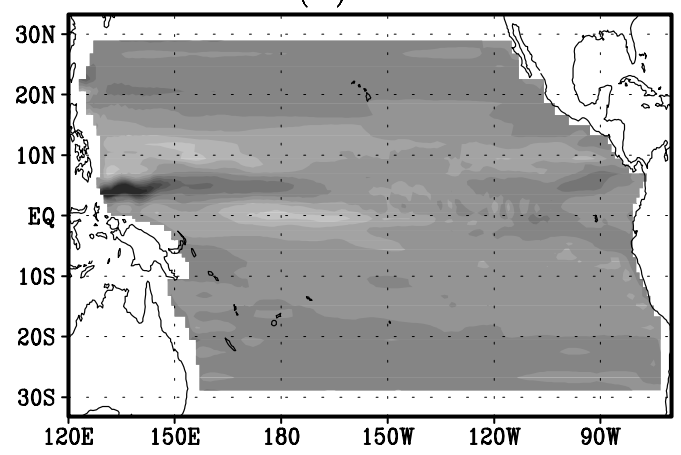

(e) $t=6$

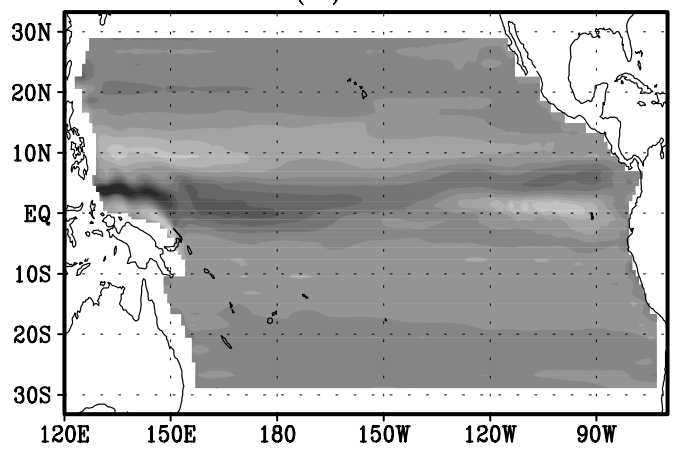

(b) $t=1$

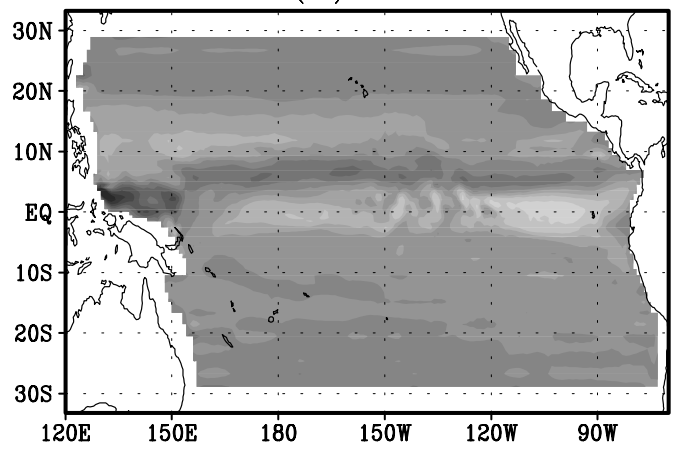

(d) $t=3$

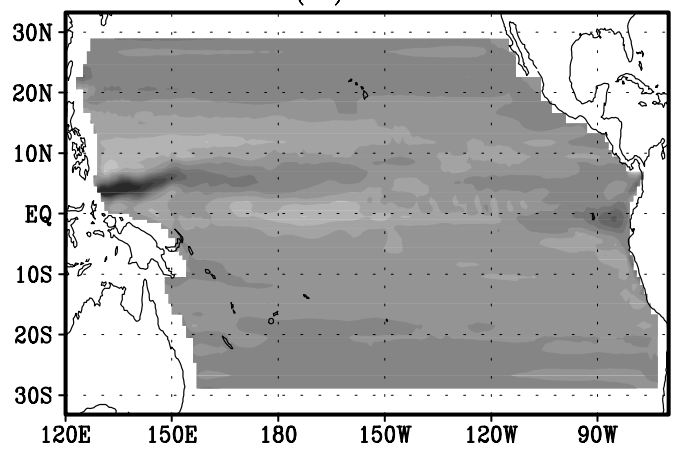

(f) $t=6$

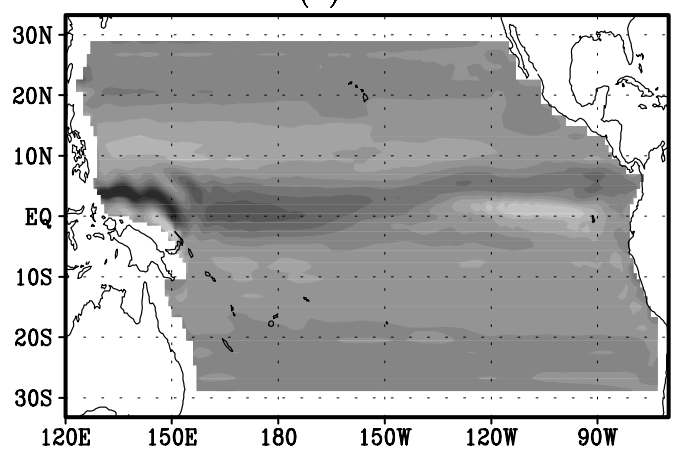

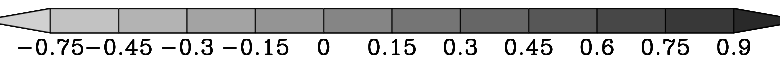

Figure 12. The predicted zonal current $u$, initialized from the off-line scheme (left) and the traditional assimilation scheme (right) at several lead times. See color version of this figure at back of this issue.

Although the off-line scheme led to some imbalances between the model dynamical and thermal variables, the imbalances were found to be relatively small, and quickly adjusted during the prediction run via geostrophic adjustment. As such, the imbalances had little impact on the model prediction skill. In fact, the prediction skills achieved by the off-line schemes were almost as good as those initialized by the traditional assimilation scheme as shown in Figure 13, which compares the prediction skills of Niño3 SSTA initialized by the two schemes. In Figure 13, the period of 1993-1998 was chosen because it contains the strongest El Niño event and also has been used by ECMWF to test a 3D-Var and 4D-Var assimilation system using the same OGCM as here [Weaver et al., 2003; Vialard et al., 2003]. Considering that the off-line scheme only requires around $1 / 20$ computational expense of the traditional 2D-
Var algorithm used in Figure 13, we conclude that the offline scheme is practically useful and powerful.

[43] An interesting question that we haven't discussed so far is whether the NCEP data can directly initialize the OGCM for improving the prediction skills, as by Syu and Neelin [2000]. Compared with the off-line scheme, the direct strategy used by Syu and Neelin [2000] is even simpler, as it only requires to interpolate the NCEP data

Table 2. Correlation and RSES of Zonal Surface Current $u$ Between Two Schemes

\begin{tabular}{cccc}
\hline & $t=1$ & $t=3$ & $t=6$ \\
\hline Correlation coefficient & 0.83 & 0.87 & 0.96 \\
RSES & 0.45 & 0.23 & 0.09 \\
\hline
\end{tabular}



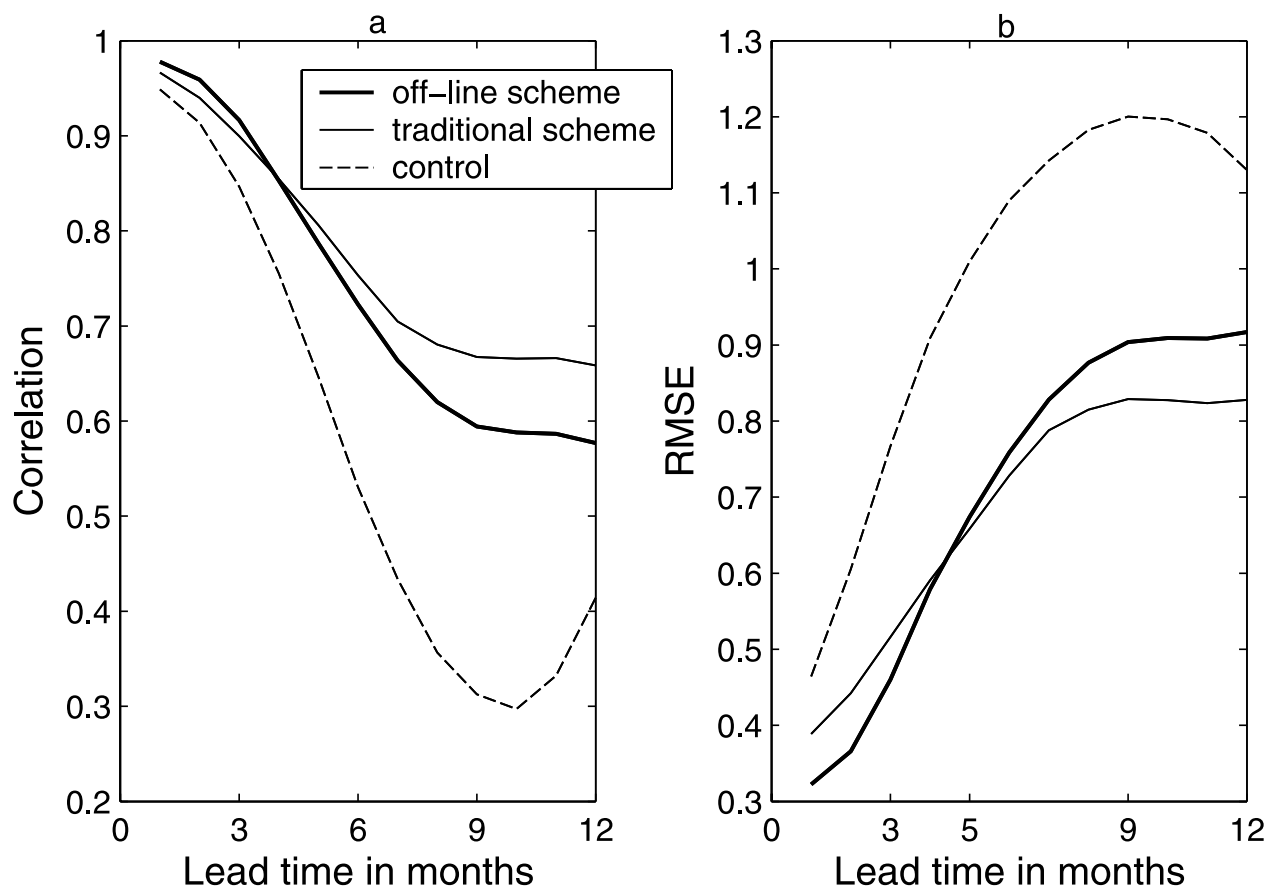

Figure 13. (a) Correlation and (b) RMSE between observed and predicted SST anomalies with HCM1 in the Niño3 region, as a function of lead time. The predictions are initialized every month from January 1993 to December 1998. Thick line is from the prediction initialized from the off-line scheme, dashed line is from the prediction initialized from the control run, and thin line is from the traditional assimilation scheme.
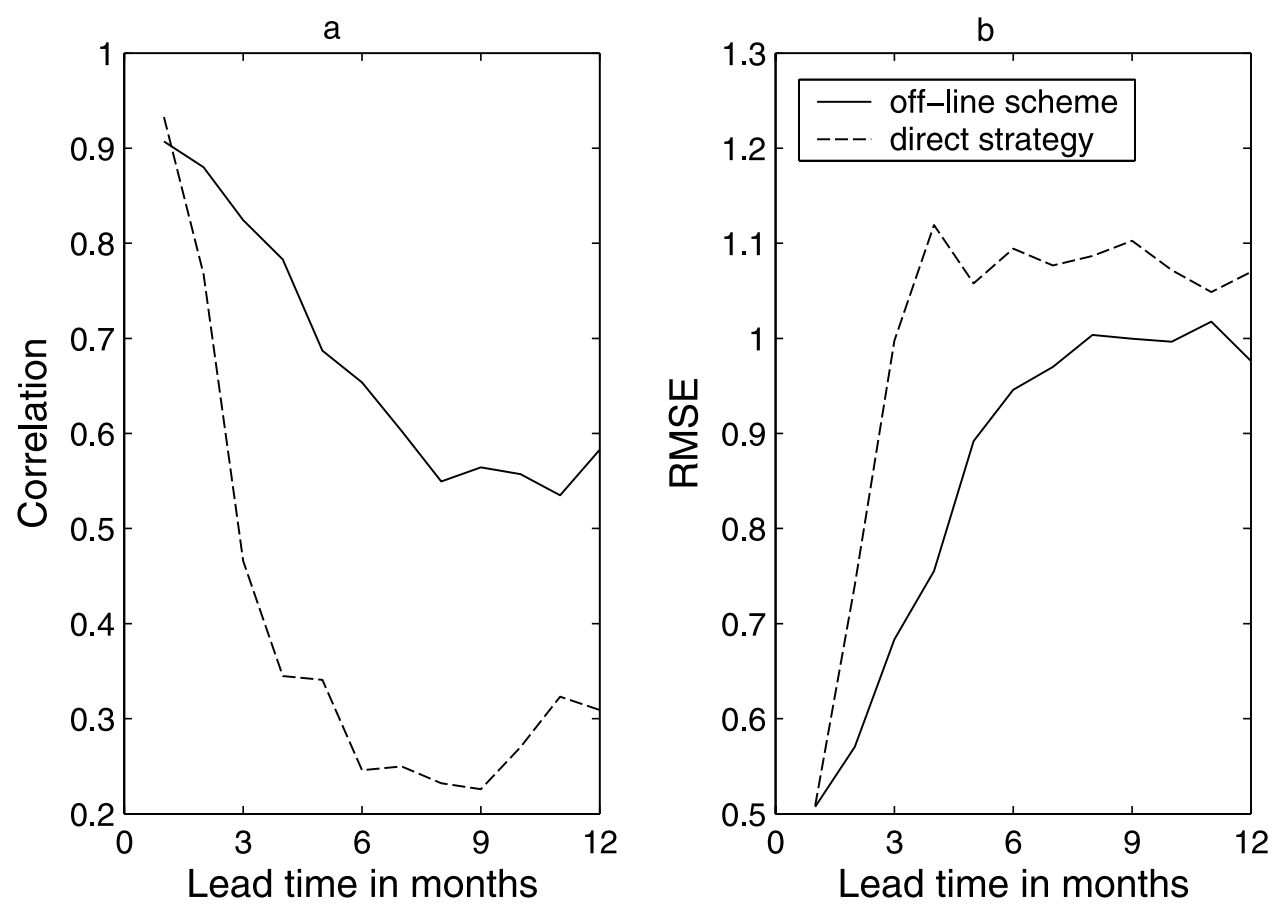

Figure 14. (a) Correlation and (b) RMSE between observed and predicted SST anomalies in the Niño3 region, as a function of lead time. The predictions are initialized every 3 months from January 1981 to December 1998 with model 1. Solid line is from the prediction initialized from the off-line scheme. Dashed line is from the prediction initialized from the direct strategy, i.e., simply interpolating the NCEP data to model grids. 
to the model grid and there is no optimization involved. In fact, the direct strategy is a specific case of the off-line scheme. With the weights to the model background set to zero, namely the reanalysis data is assumed to provide all useful information, the off-line scheme simply becomes the direct strategy. This assumption might approximately hold if the model that is to be initialized is very similar to that which generated the reanalysis data set (for example as in the study of Syu and Neelin [2000]). However, as the model used for the reanalysis data set is generally rather different from that which is to be initialized, the reanalysis data contains inconsistent information concerning background state. As a consequence, the model background should be included in the scheme. Figure 14 shows the prediction skills of HCM1 initialized by the direct strategy. Compared with Figure 2, the direct strategy leads to significantly worse skill than our off-line scheme, an in fact worse than the control run. This is possibly because the direct strategy introduces considerable inconsistency into the model, leading to big dynamical imbalance amongst the model variables.

[44] Acknowledgment. This work is supported by NSF grant 25-74200-F0960.

\section{References}

Barnett, T. P., M. Latif, N. E. Graham, M. Flügel, S. Pazan, and W. White (1993), ENSO and ENSO related predictability, Part 1: Prediction of equatorial sea surface temperature with a hybrid coupled ocean-atmosphere model, J. Clim., 6, 1545-1566.

Battisti, D. S. (1988), Dynamics and thermodynamics of a warming event in a coupled tropical atmosphere-ocean model, J. Atmos. Sci., 45, 2889 2919.

Battisti, D. S., and E. S. Sarachik (1995), Understanding and predicting ENSO, Rev. Geophys., 33, 1367-1376.

Behringer, D. M., M. Ji, and A. Leetmaa (1998), An improved coupled model for ENSO prediction and implications for ocean initialization, part I, The ocean data assimilation system, Mon. Wea. Rev., 126, 1013-1021.

Blanke, B., and P. Delecluse (1993), Variability of the tropical Atlantic Ocean simulated by a general circulation model with two different mixed layer physics, J. Phys. Oceanogr., 23, 1363-1388.

Burgers, G., M. A. Balmaseda, F. C. Vossepoel, G. J. van Oldenborgh, and P. J. van Leeuwen (2002), Balanced ocean-data assimilation near the equator, J. Phys. Oceanogr., 32, 2509-2519.

Derber, J., and A. Rosati (1989), A global oceanic data assimilation system, J. Phys. Oceanogr., 19, 1333-1347.

Efron, B., and R. J. Tibshirani (1993), An Introduction to the Bootstrap, 436 pp., Chapman and Hall, New York.

Gill, A. E. (1980), Some simple solutions for heat induced tropical circulation, Q. J. R. Meteorol. Sci., 106, 447-462.

Gill, P. E., W. Murray, and M. H. Wright (1981), Practical Optimization, 401 pp., Academic, San Diego, Calif.
Ji, M., R. W. Reynolds, and D. W. Behringer (2000), Use of TOPEX/ Poseidon sea level data for ocean analyses and ENSO prediction: Some early results, J. Clim., 13, 216-231.

Kleeman, R. (1989), A modeling study of the effect of the Andes on the summertime circulation of tropical South America, J. Atmos. Sci., 46, 3344-3362.

Kleeman, R., and S. B. Power (1995), A simple atmospheric model of heat flux for ocean model studies, J. Phys. Oceanogr., 25, 92-105.

Kleeman, R., A. Moore, and N. R. Smith (1995), Assimilation of subsurface thermal data into a simple ocean model for the initialization of an intermediate tropical coupled ocean-atmosphere forecast model, Mon. Wea. Rev., 123, 3103-3113.

Madec, G., P. Delecluse, M. Imbard, and C. Levy (1999), OPA 8.1 Ocean General Circulation Model Reference Manual, 91 pp., Inst. Pierre Simon Laplace, Paris, France.

McPhaden, M. J., et al. (1998), The Tropical Ocean Global Atmosphere (TOGA) observing system: A decade of progress, J. Geophys. Res., 103, $14,169-14,240$.

Schopf, P. S., and M. J. Suare (1988), Vacillations in a coupled oceanatmosphere model, J. Atmos. Sci., 45, 549-566.

Segschneider, J., D. L. T. Anderson, J. Vialard, M. Balmaseda, and T. N. Stockdale (2002), Initialization of seasonal forecasts assimilating sea level and temperature observations, J. Clim., 14, 4292-4307.

Smith, T. M., R. W. Reynolds, R. E. Livezey, and D. C. Stokes (1996), Reconstruction of historical sea surface temperatures using empirical orthogonal functions, J. Clim., 9, 1403-1420.

Syu, H.-H., and D. Neelin (2000), ENSO in a hybrid coupled model. Part II: Prediction with piggyback data assimilation, Clim. Dyn., 16, 35-48.

Troccoli, A., and K. Haines (1999), Use of the temperature? Salinity relation in a data assimilation context, J. Atmos. Ocean. Technol., 16, 2011-2025.

Vialard, J., P. Delecluse, and C. Menkes (2002), A modeling study of salinity variability and its effects in the tropical Pacific Ocean during the 1993-1999 period, J. Geophys. Res., 107(C12), 8005, doi:10.1029/ 2000JC000758.

Vialard, J., A. T. Weaver, D. L. T. Anderson, and P. Delecluse (2003), Three- and four-dimensional variational assimilation with a general circulation model of the tropical Pacific Ocean, Part 2: Physical validation, Mon. Wea. Rev., 131, 1379-1395.

Weaver, A. T., J. Vialard, and D. L. T. Anderson (2003), Three- and fourdimensional variational assimilation with a general circulation model of the tropical Pacific Ocean, Part 1: Formulation, internal diagnostics and consistency checks, Mon. Wea. Rev., 131, 1360-1378.

White, W. B. (1995), Design of a global observing system for gyre-scale upper ocean temperature variability, Prog. Oceanogr., 36, 169-217.

R. Kleeman and Y. Tang, Courant Institute of Mathematical Sciences, New York University, 251 Mercer Street, New York, NY 10012, USA. (ytang@cims.nyu.edu)

A. M. Moore, Program for Atmosphere Ocean Science, University of Colorado, Boulder, CO 80309, USA.

A. Weaver, Climate Modeling and Global Change Group, Climate Modeling and Global Change Group Centre Europen de Recherche et de Formation Avance en Calcul Scientifique, Toulouse F-1875, France. (weaver@cerfacs.fr)

J. Vialard, Laboratoire d'Oceanographie Dynamique et de Climatologie, Paris F-75454, France. (jv@lodyc.jussieu.fr) 

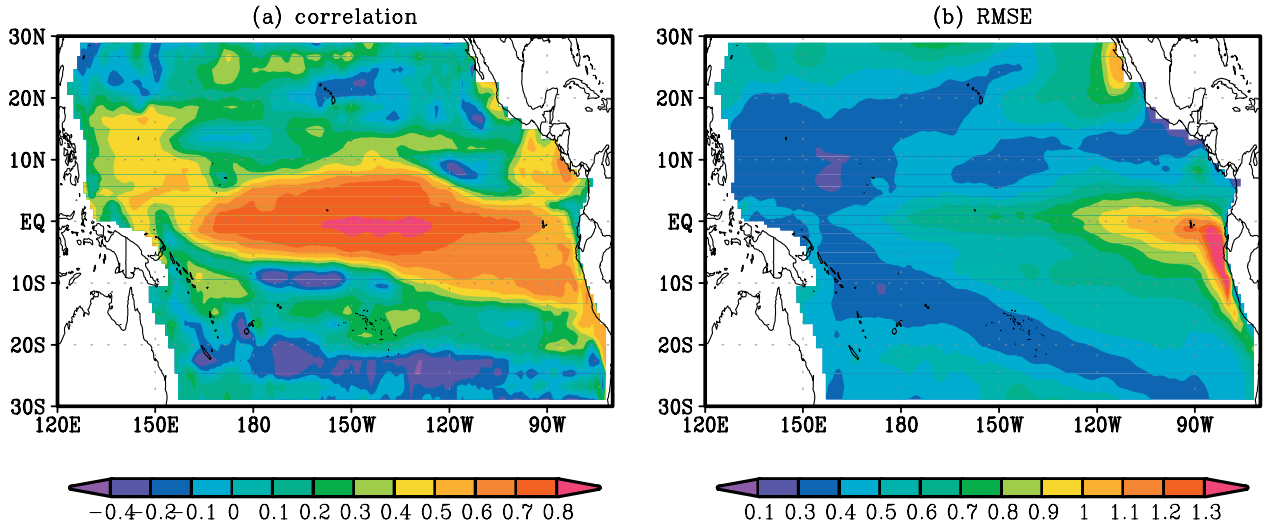

Figure 1. (a) Correlation and (b) RMSE between observed and modeled sea surface temperature (SST) anomalies derived from the control run forced with the National Centers for Environmental Prediction (NCEP) wind, from 1981 to 1999.

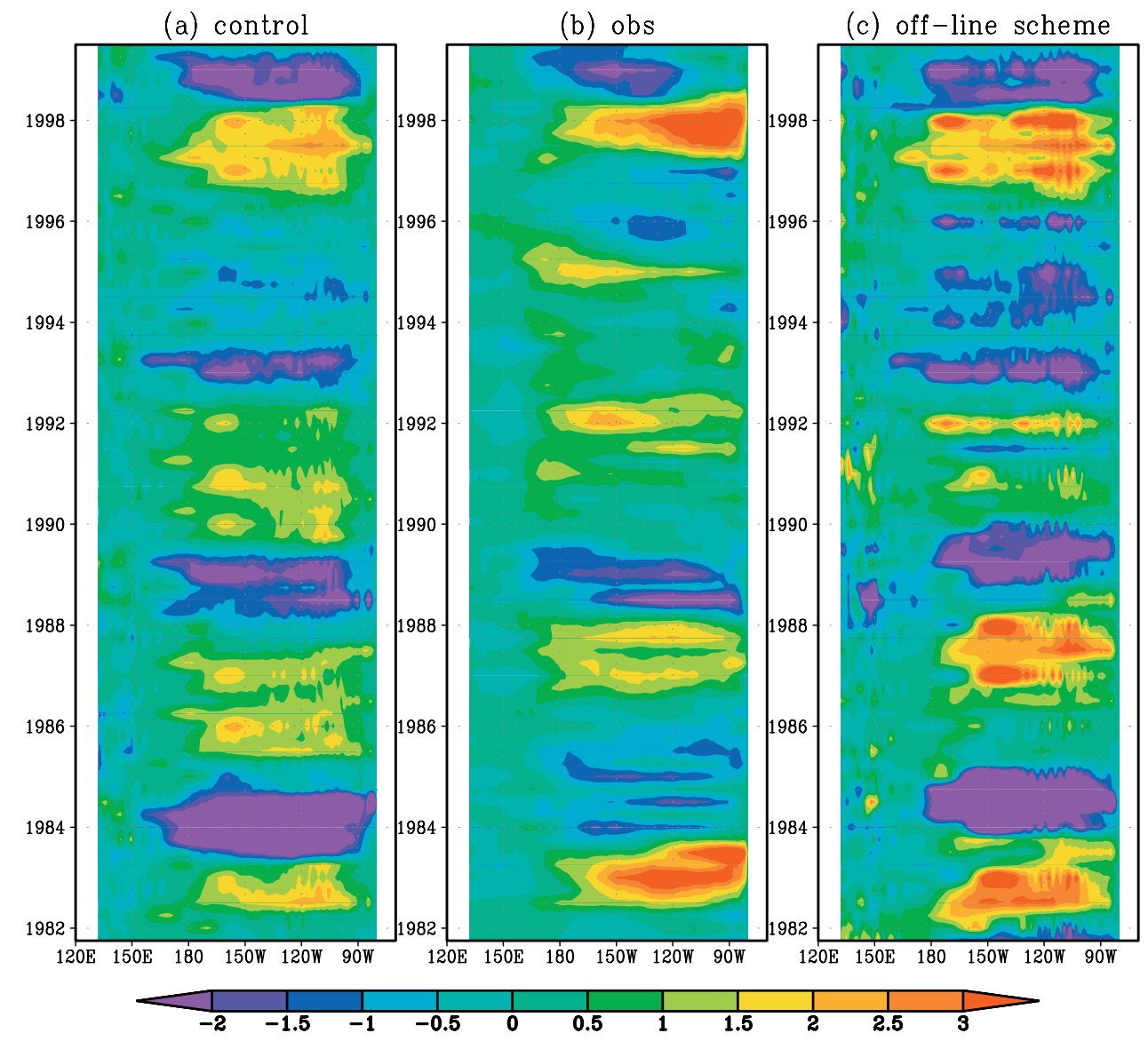

Figure 3. Time-longitude diagrams of predicted sea surface temperature anomaly (SSTA) with HCM1 along the equator at the lead time of 9 months, initialized by the (a) control run and by (c) the off-line scheme. For comparison, (b) the observed SSTA is shown. 
(a) HCM1- control

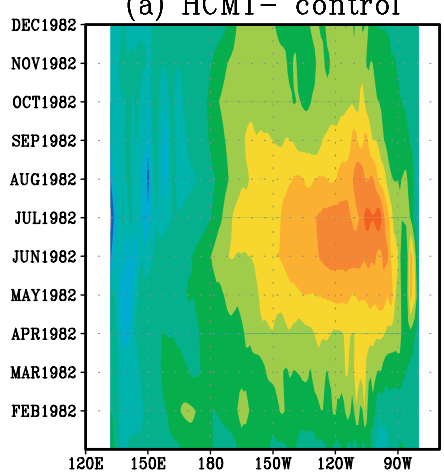

(d) HCM2- control

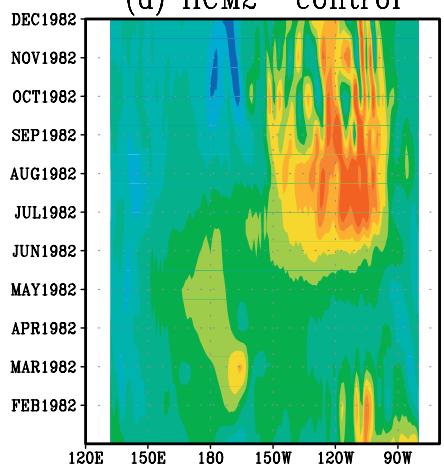

(b) HCM1- off-line scheme

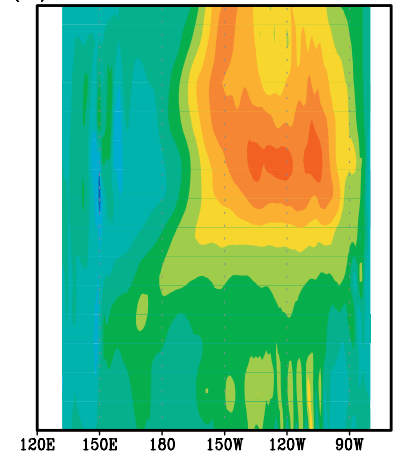

(e) HCM2- off-line scheme

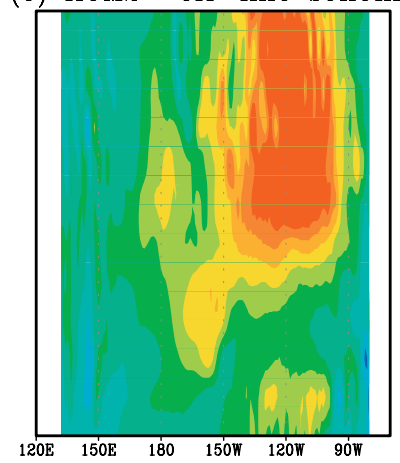

(c) observation
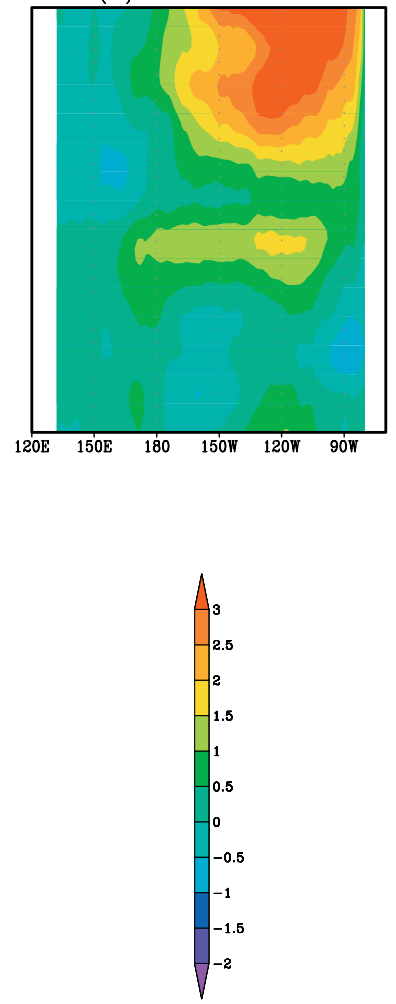

Figure 4. Time-longitude diagrams of predicted SSTA along the equator for the 1982/83 warm event. The predictions were carried out with the two hybrid coupled models (HCMs), initialized by the control run and the off-line scheme, on 1 January 1982. For comparison, the observed SSTA is shown. 
(a) HCM1- control

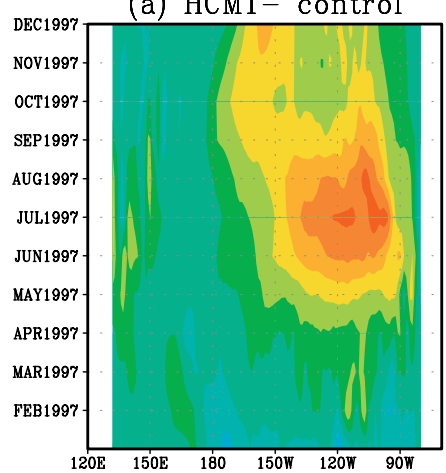

(d) HCM2 - control

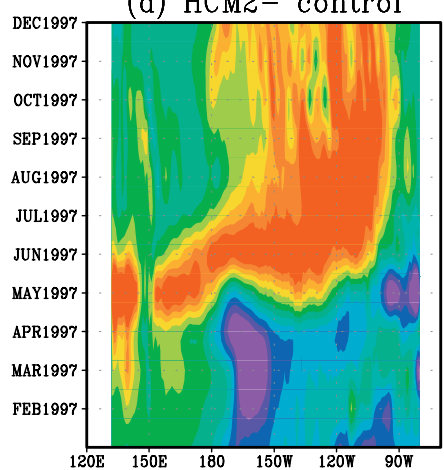

(b) HCM1- off-line scheme

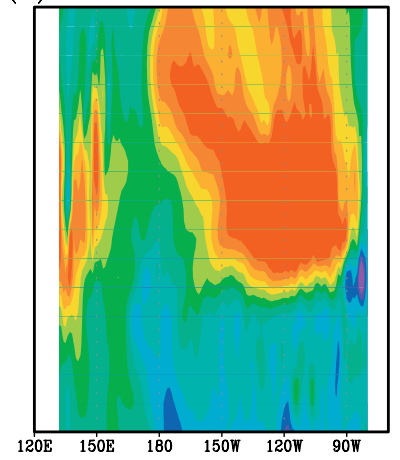

(e) HCM2- off-line scheme

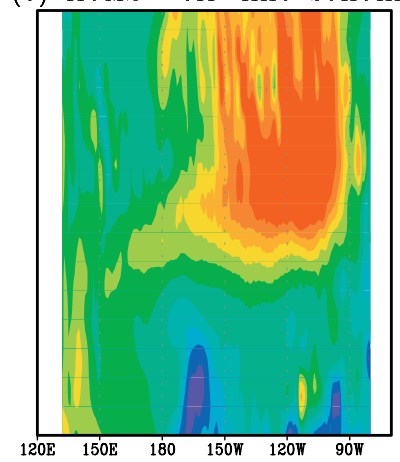

(c) observation
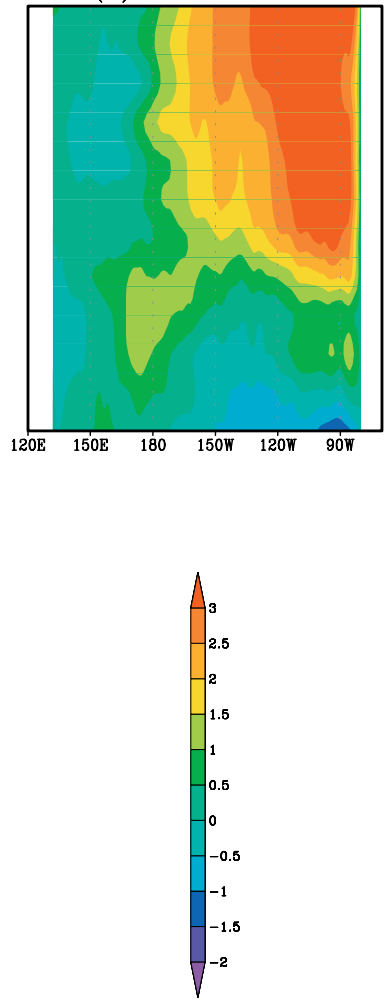

Figure 5. Same as in Figure 4 but for the 1997 warm event. The prediction was initialized on 1 January 1997.

(a) HCM1 - control

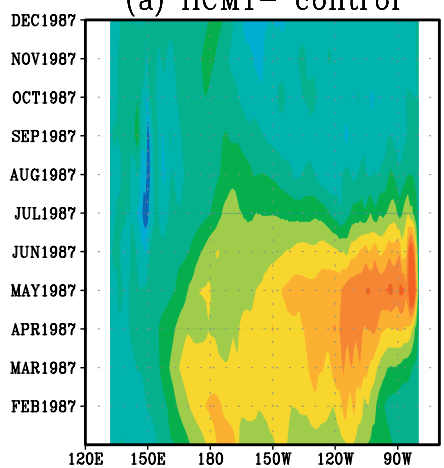

(d) HCM2- control

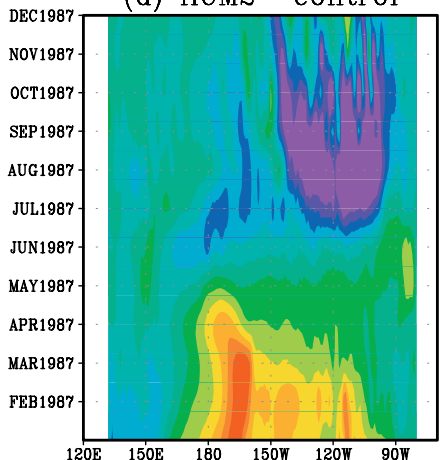

(b) HCM1- off-line scheme

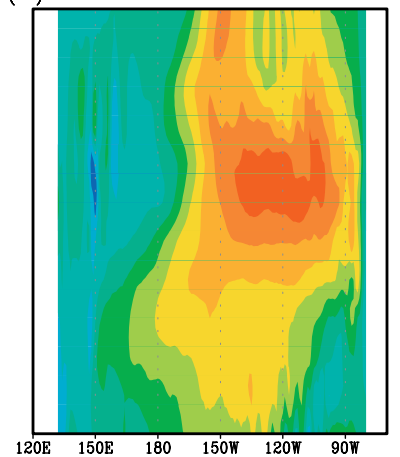

(e) HCM2- off-line scheme

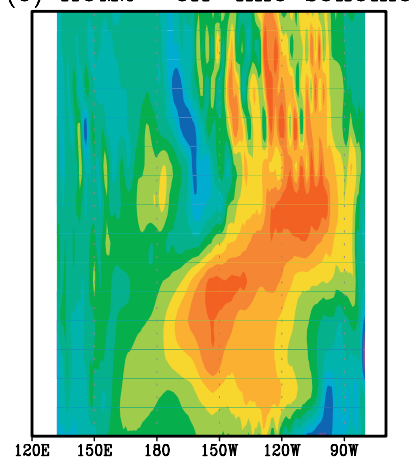

(c) observation
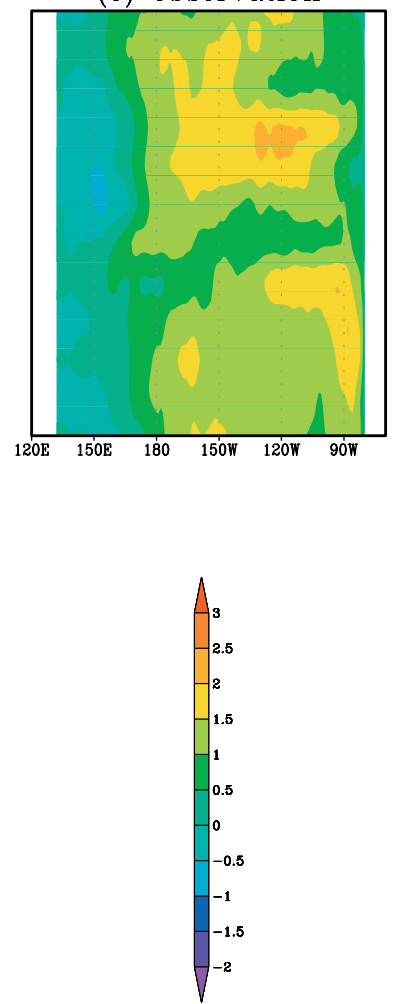

Figure 6. Same as in Figure 4 but for the 1987 warm event. The prediction was initialized on 1 January 1987. 
(a) $t=1$

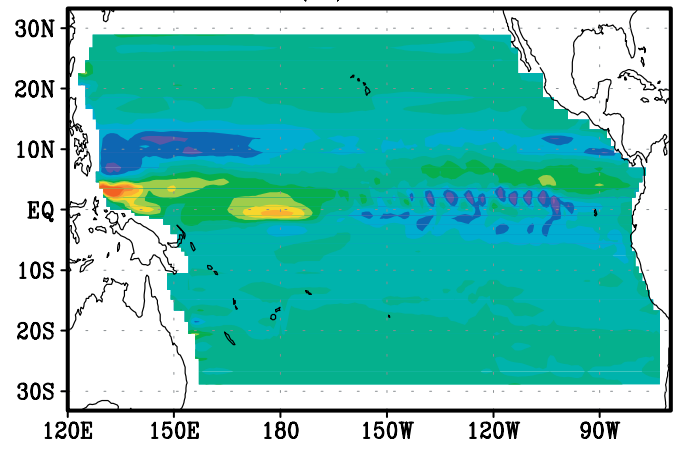

(c) $t=12$

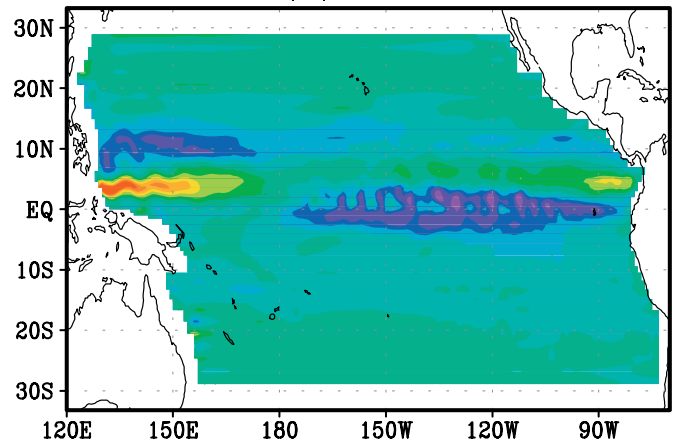

(e) $t=24$

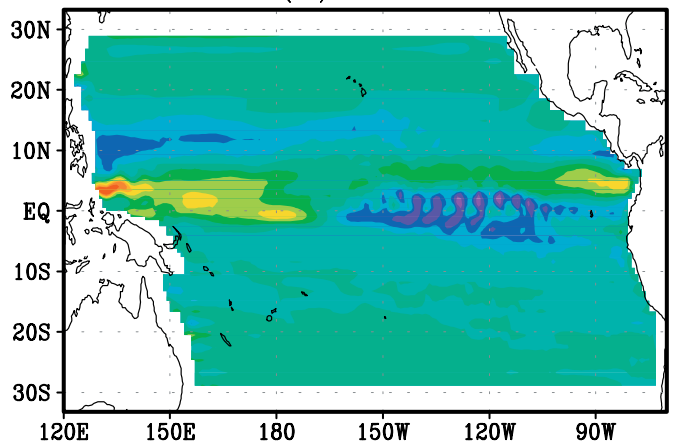

(b) $t=1$

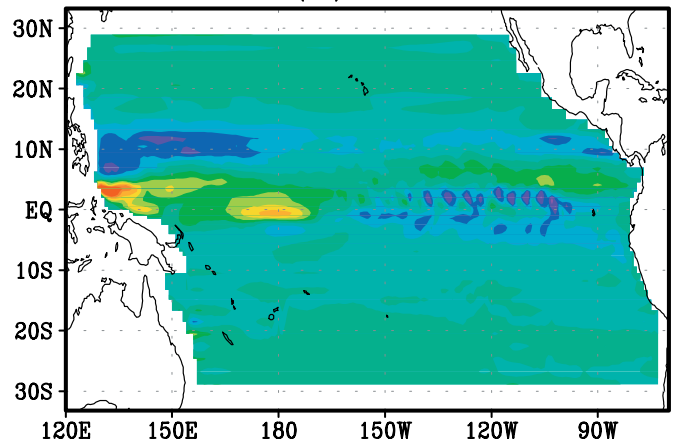

(d) $t=12$

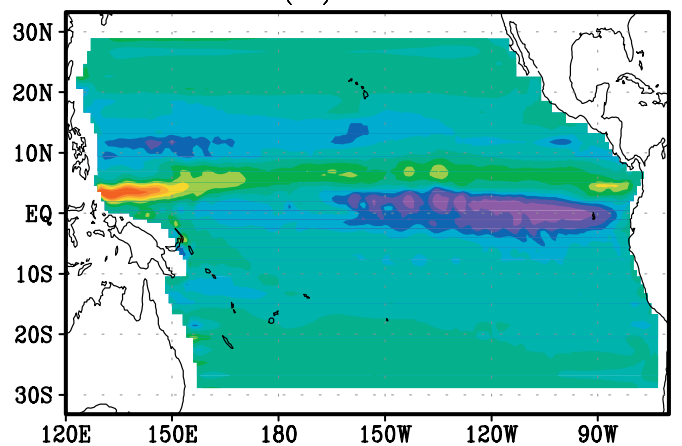

(f) $t=24$

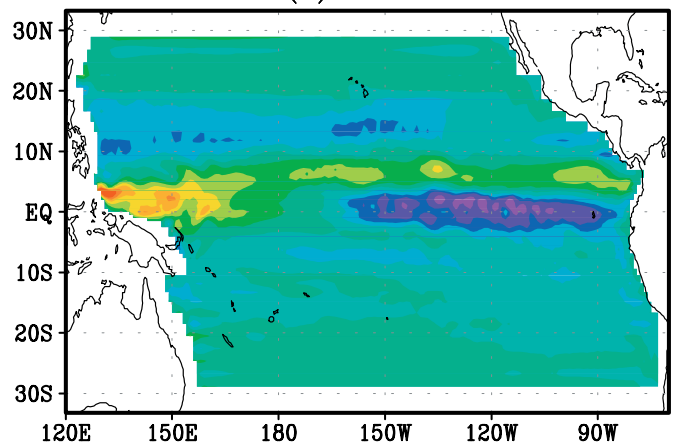
$\begin{array}{llllllll}-0.75-0.45-0.3-0.15 & 0 & 0.15 & 0.3 & 0.45 & 0.6 & 0.75 & 0.9\end{array}$

Figure 11. The velocity of the surface zonal current $(u)$ from the off-line scheme (left) and traditional assimilation scheme (right) at three different times. 
(a) $t=1$

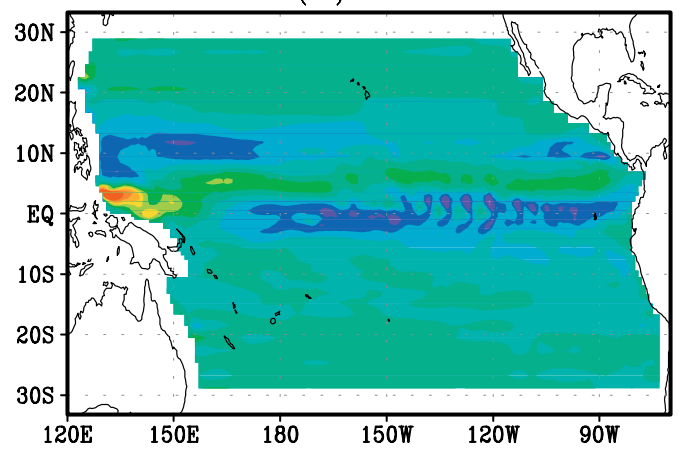

(c) $t=3$

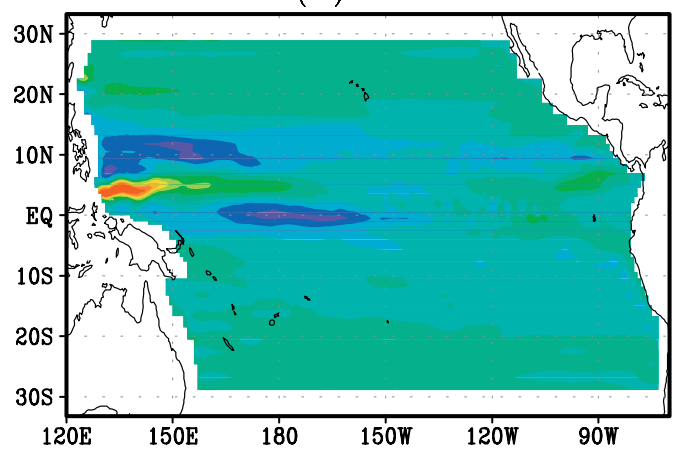

(e) $t=6$

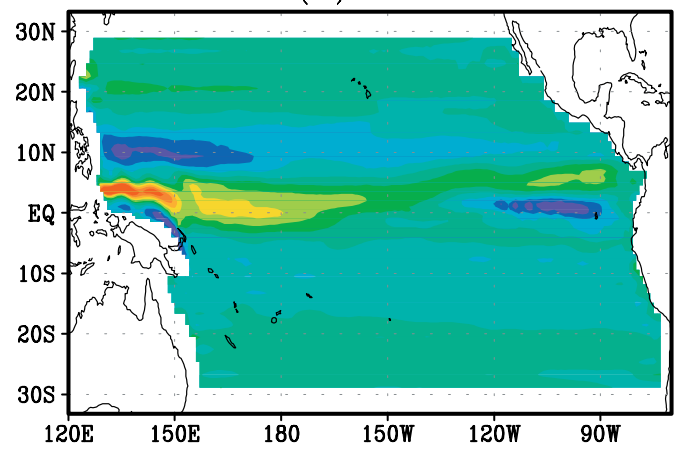

(b) $t=1$

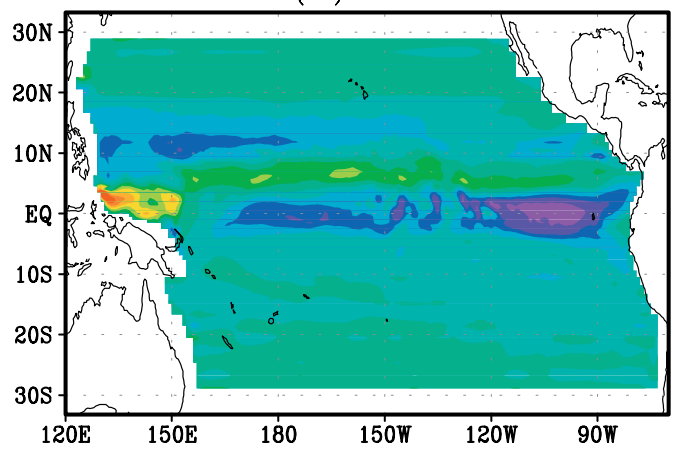

(d) $t=3$

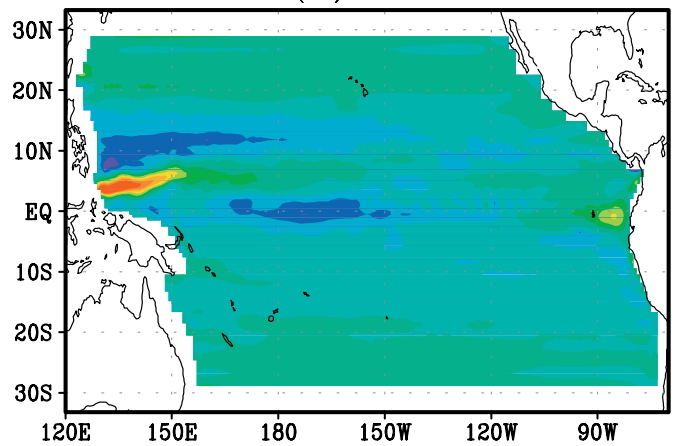

(f) $t=6$

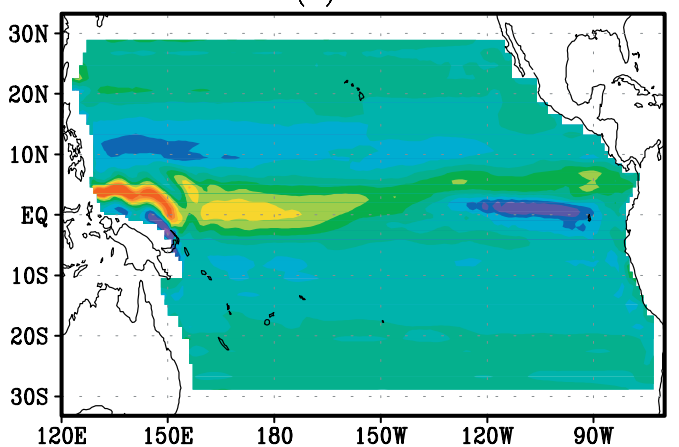

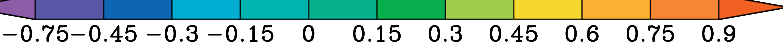

Figure 12. The predicted zonal current $u$, initialized from the off-line scheme (left) and the traditional assimilation scheme (right) at several lead times. 